\title{
Basic Value Orientations and Moral Foundations: Convergent or Discriminant Constructs?
}

\author{
Alexandra Zapko-Willmes ${ }^{1}$, Shalom H. Schwartz ${ }^{2}$, Julia Richter ${ }^{3}$, and Christian Kandler ${ }^{1}$ \\ ${ }^{1}$ University of Bremen, ${ }^{2}$ The Hebrew University of Jerusalem, ${ }^{3}$ Bielefeld University
}

This is a preprint version of a manuscript accepted for publication in the Journal of Research in Personality. https://doi.org/10.1016/j.jrp.2021.104099

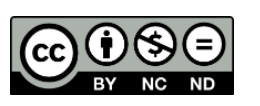

Author Note.

\begin{abstract}
Alexandra Zapko-Willmes and Christian Kandler, Department of Psychology, University of Bremen, Bremen, Germany.

Shalom H. Schwartz, Department of Psychology, The Hebrew University of Jerusalem, Jerusalem, Israel.

Julia Richter, Department of Psychology, Bielefeld University, Bielefeld, Germany. Correspondence concerning this article should be addressed to Alexandra Zapko-Willmes (a.zapkowillmes@uni-bremen.de).
\end{abstract}

The data analyzed in this paper have been collected in the Study of Personality Architecture and Dynamics (www.speady.de), supported by the Deutsche Forschungsgemeinschaft (DFG) KA 4088/2-1 (Grant number: 272981829). The funding source was not involved in study design, collection, analysis, and interpretation of data, writing of the report, or the decision to submit the article for publication. Part of the content of the paper was presented as at the European Conference on Personality (ECP) 2018 in Zadar, Croatia, at the meeting of the German Psychological Association (DGPs) 2018 in Frankfurt, Germany, and at the World Conference on Personality (WCP) 2019 in Hanoi, Vietnam. 


\begin{abstract}
This study examined the structural and genetic links between value orientations, based on the theory of basic values, and moral concerns, based on moral foundations theory. We hypothesized both structural and genetic convergence of Conservation (versus openness to change) with Binding foundations and of Self-transcendence (versus self-enhancement) with Individualizing foundations. We analyzed self- and informant ratings from 924 participants with extended multitrait-multirater modeling and ran twin model analyses on self-ratings from 555 twin pairs. For Conservation and Binding foundations, we found partial convergence across different rater perspectives and a substantial genetic overlap, but also distinct genetic factors. Self-transcendence and Individualizing foundations were found to be structurally divergent, but genetically linked. We discuss the conceptual and measurement-related implications of the findings.

Keywords: basic values; moral foundations; multi-rater study; twin study
\end{abstract}




\section{Introduction}

Values as conceptualized in the theory of basic human values (TBV) and moral foundations as defined in Moral Foundations Theory (MFT) are psychological constructs that share many similarities of function, structure, and content (Haidt \& Joseph, 2004, 2007; Schwartz, 1992, 1994; Schwartz et al., 2012). Past research into the nature of their links has been inconclusive (Feldman, 2018; Graham et al., 2011; Sverdlik, Roccas, \& Sagiv, 2012). Despite the lack of clarity regarding their empirical distinctiveness, some studies have used key value and moral foundation measures interchangeably (Feldman, Chao, Farh, \& Bardi, 2015; Fritzsche \& Oz, 2007; Mamsori, Rezaee, Homayoun, \& Noghondari, 2015).

The current research seeks to clarify how value orientations and moral foundations converge or diverge, thereby shedding light on the validity of the structural and source-related distinctiveness of these constructs (Cronbach \& Meehl, 1955; Le, Schmidt, Harter, \& Lauver, 2010; Shaffer, DeGeest, \& Li, 2016). If the TBV and MFT frameworks express the same characteristics, research would benefit from a narrow, consistent, and psychometrically sound operationalization of the underlying constructs. This would also provide deeper insight into the associations of these constructs with other characteristics, such as personality traits (Lee, Ashton, Ogunfowora, Bourdage, \& Shin, 2010), ideological attitudes (e.g., Sinn, 2019), and voting behavior (Schwartz, Caprara, \& Vecchione, 2010). We used multi-rater data to investigate the dimensions' common structural basis within and across self- and informant reports. With twin family data, we estimated genetic and environmental contributions to the common and specific variance in measures of value priorities and moral concerns.

\subsection{On Values and Moral Concerns}

Values as evaluative concepts and moral concerns as a form of evaluative judgments can be seen as connected insofar as "evaluative concepts are used to assess the worth of things" and "evaluative judgements express such assessments" (Tappolet \& Rossi, 2016, pp. 6-7). This suggests that moral judgments are expressions of values. However, given the spectrum of both constructs, it bears asking whether there are "nonmoral" values (i.e., values that do not affect moral judgments and, consequently, are not expressed as moral judgments) and whether there are other factors affecting moral judgments (e.g., based on other individual or environmental characteristics). Moreover, the existence of partly conflicting psychological theories on both constructs has impeded insight into the links between them.

\subsubsection{Basic Values}


Values have been investigated for more than a century (e.g., Urban, 1907). In 1931, Allport and Vernon were the first who empirically studied values (as cited in Bilsky, 2008). From the 1950s onwards, other conceptualizations of values appeared (e.g., Heider, 1958; Kluckhohn, 1951; Morris, 1956; Parsons, 1951) and sparked criticism (e.g., Adler, 1956; Campbell, 1963; Levitin, 1968; Smith, 1969). The seminal, path-breaking work of Rokeach (1973) introduced some consensus into conceptualizing and measuring values. Rokeach selectively combined several key assumptions of previous research (while discarding others) with an intuitive set of values. His view of values as both modes of conduct and end-states led him to operationalize value contents in a new way (Braithwaite \& Scott, 1991). Building on Rokeach, Schwartz and Bilsky $(1987,1990)$ formulated a motivational framework of the basic values that may be recognized across cultures. This theory is currently the most wellestablished and widely used.

Schwartz and Bilsky $(1987,1990)$ defined values as trans-situational beliefs about the importance of desirable goals that motivate behaviors and serve as standards for evaluating entities (i.e., events, actions, organizations, and people). They postulated that values represent the motivational contents needed to satisfy individual biological needs, regulate social interactions, and preserve group well-being and survival. They theorized that values form a circular continuum based on the compatibility and conflict among their motivational goals (Schwartz, 1992). Studies in more than 75 countries have validated the circular continuum of the original theory that initially included 10 basic values (Schwartz, 2015). Schwartz et al. (2012) later refined the original theory by partitioning the circular continuum into 19 distinguishable values, which was validated by studies across 31 countries (Schwartz, 2017).

Values typically guide choices outside of conscious awareness (Schwartz, 2016). They enter awareness mainly when making a decision arouses conflict between important values. Individuals assign varying degrees of importance to each of their values as guiding principles in their life to form their value hierarchy. In the circular motivational continuum of values, adjacent values are compatible and opposing values are incompatible. Schwartz (1992) summarized the value circle by identifying two sets of motivationally opposed higher-order values that form the poles of two (almost orthogonal) dimensions. An openness to change vs. conservation dimension (in the following Conservation) captures the conflict between values that emphasize independent thought, action, and feelings, challenge, and change and values that emphasize self-restriction, preserving the past, order, and resistance to change. A selfenhancement vs. self-transcendence dimension (in the following Self-transcendence) captures the 
conflict between values that emphasize concern for the welfare and interests of others and values that emphasize concern for one's own interests, relative success, and dominance over others.

\subsubsection{Moral Foundations}

The works of Piaget (1932/2015) and Kohlberg (1963) profoundly shaped the developmental and educational psychology approaches to moral judgment in the 20th century (Skitka \& Conway, 2019). Since the turn of the millennium, however, competing descriptive models have replaced these prescriptive perspectives (Gray \& Graham, 2018). These models have (re-)introduced formerly neglected aspects of moral judgment, such as intuitions (Haidt, 2001) and emotions (Greene, Sommerville, Nystrom, Darley, \& Cohen, 2001). They have also sparked a debate concerning the moral domain itself (e.g., pluralism vs. monism; Graham, 2015; Gray \& Keeney, 2015a, 2015b). Current views differ regarding both the functions and functioning of moral judgment. They approach morality from its social function (Curry, Jones Chesters, \& Van Lissa, 2019; Rai \& Fiske, 2011), its links with motivational approachavoidance mechanisms (Janoff-Bulman \& Carnes, 2013), or its interwovenness with intuitive, synthetic harm perception (Schein \& Gray, 2018). The three most cited seminal papers on moral reasoning in the last eight decades center around ideas from Moral Foundations Theory (Ellemers, van der Toorn, Paunov, \& van Leeuwen, 2019). We therefore view MFT as the dominant current approach to morality.

MFT couples the dual-system conceptualization of thinking (e.g., Kahneman, 2011) with evolutionary and anthropological considerations (Haidt \& Joseph, 2004, 2007). Moral judgments as "evaluations (good vs. bad) of the actions or character of a person that are made with respect to a set of virtues held to be obligatory by a culture or subculture" (Haidt, 2001, p. 817) involve two cognitive processes, moral intuitions and moral reasoning (Graham et al., 2018). Moral reasoning requires intentional and effortful conscious mental information processing, whereas moral intuitions are automatic, quick, and effortless. Moral intuitions are a "sudden appearance in consciousness of a moral judgment, including an affective valence (good-bad, like — dislike), without conscious awareness of having gone through steps of searching, weighing evidence, or inferring a conclusion" (Haidt, 2001, p. 818). Moral intuitions have primacy in forming moral judgments. However, moral reasoning that supports and rationalizes the initial, intuitive reactions may ensue (Graham et al., 2011; Haidt \& Kesebir, 2010).

MFT defines transculturally valid virtues or modules of moral intuition called moral foundations (Graham, Meindl, Beall, Johnson, \& Zhang, 2016). These moral foundations constitute an innate mental structure of moral judgment that is theorized to have evolved due 
to its advantages for the individual, inclusive, and group-level fitness (Haidt \& Kesebir, 2010) ${ }^{1}$. In other words, Haidt and Kesebir (2010) argued that both interindividual competition within groups and intergroup competition shaped moral judgment. Moral foundations promote (intuitive) protection of kin, coordinate profitable cooperation and handling of cheating, strengthen the group's control over resources, facilitate navigation through complex hierarchical structures, and protect against parasites and (communicable) diseases. A total of five moral foundations form two dimensions, based on their "locus of moral value" (Graham, Haidt, \& Nosek, 2009, p. 1030). These dimensions, Binding foundations and Individualizing foundations, reflect different systems for regulating selfish behaviors. Binding foundations express a concern for transgressions on a group level through adherence to hierarchical structures, tradition, and concern for social order (authority), for obligations regarding one's group affiliation (loyalty), and for spiritual purity and body integrity (sanctity). Individualizing foundations emphasize protecting individuals through concern for the well-being of others (care) and for justice, proportionality, and autonomy (fairness).

\subsection{Divergence or Convergence?}

In the last ten years, psychological research has moved toward an integration of values and moral foundations (Goodwin, Williams, \& Snell Herzog, 2020). Indeed, despite different theoretical and methodological approaches, basic value dimensions and moral foundations overlap in function, cognitive-affective mechanisms, and content. They both serve as necessary responses to three human existential demands posed by the environment: They satisfy biological needs, coordinate and structure social interactions, and ensure group functioning and survival (Haidt \& Joseph, 2004, 2007; Schwartz, 1992, 1994). They both involve unconscious cognitive processes and affective responses (Fede \& Kiehl, 2020; Moll, Zahn, de Oliveira-Souza, Krueger, \& Grafman, 2005; Schwartz, 2016; Zahn et al., 2009). And their structures coincide in content: Conservation and Binding foundations focus on giving priority to security and stability, and Self-transcendence and Individualizing foundations focus on giving priority to social issues. Past studies confirmed these parallels but differed in their conclusions about their associations (Feldman, 2018; Graham et al., 2011; Sverdlik et al., 2012).

\footnotetext{
${ }^{1}$ Notably, individual selection and group selection are typically not considered to be complimentary. Rather, there is a longstanding, controversial debate between proponents of these concepts of selection (e.g., Abbott et al., 2011; Nowak, Tarnita, \& Wilson, 2010).
} 
Defining numerical estimates of convergence is a difficult matter; plausible expectations have to be taken into account (Cronbach \& Meehl, 1955). In keeping with Campbell and Fiske's (1959) recommendations, full convergence would show when the amount of (co-)variance explained by a common construct-valid factor significantly exceeds (co-)variance contributions from method- and dimension-specific factors. Ergo, a common factor should account for more than $50 \%$ of true score variance (i.e., variance corrected for measurement error) in both dimensions. Lower proportions of explained variance due to the common factor would imply construct divergence. Importantly, dimensions may also partially converge (see 1.2.2.). A dimension may entirely comprise a part of the content space of another dimension. Hence, for partial convergence, a common factor should explain more than $50 \%$ of true score variance in one dimension above and beyond other factors.

Moreover, individual differences in convergent constructs should be attributable to common genetic sources. A full convergence would entail that a common construct-valid factor accounts for the total amount of genetic variance in both dimensions. A partial convergence would be shown when a common factor accounts for the total amount of genetic variance in only one dimension. If both dimensions show unique proportions of genetic variance, we can conclude construct divergence. It is important to take both genetic and environmental covariance into account, as genetic covariance can result from effects of heritable third variables, such as dispositional traits, whereas common environmental sources may result from socialization effects on individual differences in both dimensions. In the following, we present potential explanations for a divergence or convergence between these constructs.

\subsubsection{Divergent Constructs}

Construct divergence would be characterized by a mostly unique variance of the dimensions. Feldman (2018) investigated the links between basic value orientations and moral foundations in large multi-national samples using different self-report measures. He examined results of correlational patterns, confirmatory factor analyses, and incremental predictive validity of the two frameworks for morality-related outcomes. He concluded that basic value orientations and moral foundations are systematically related but distinct traits. Graham et al. (2011) also argued that the dimensions are distinct, based on their incremental contributions in predicting specific values as external criteria. Graham et al. (2011) speculated that basic values and moral foundations probably develop in parallel and represent the same personality layer within a broad conception of personality (McAdams \& Pals, 2006). 
McAdams and Pals (2006) differentiated three levels of personality: dispositional traits, characteristic adaptations, and integrative life narratives. Interindividual differences in characteristic adaptations show more environmental variance and are less stable over time than dispositional traits. Various findings suggest that basic value orientations show features of dispositional traits. Individual differences in value priorities are relatively stable (e.g., Bardi, Lee, Hofmann-Towfigh, \& Soutar, 2009; Milfont, Milojev, \& Sibley, 2016; Schwartz, 2005; Vecchione et al., 2016) and partly heritable (Kandler, Gottschling, \& Spinath, 2016; Keller, Bouchard, Arvey, Segal, \& Dawis, 1992; Knafo \& Spinath, 2011; Renner et al., 2012; Schermer, Vernon, Maio, \& Jang, 2011; for an exception, see Schermer, Feather, Zhu, \& Martin, 2008). Findings on the stability of moral foundations are inconsistent (Graham et al., 2011; Smith, Alford, Hibbing, Martin, \& Hatemi, 2017). Individual differences in moral foundations appear to be primarily attributable to environmental factors (Smith et al., 2017). Moral foundations are claimed to be structurally innate (Haidt \& Joseph, 2004, 2007), but they emerge in association with social and cultural influences (Haidt, 2001). Thus, moral foundations may be products of (heritable) interindividual differences in value orientations and environmental factors.

\subsubsection{Partially Convergent Constructs}

Constructs may partially converge as shown through a common factor that explains most variance in one dimension. For example, the value framework may encompass human functioning beyond the realm of moral principles (see also Higgins, 2016). One of the main controversies regarding values has focused on whether values reflect the desired or preferred as opposed to what ought to be desired or preferred (i.e., the desirable or preferable;

Braithwaite \& Scott, 1991). Rohan (2000) proposed that values, as defined by Schwartz and Bilsky, comprise both the desirable and the desired. To that extent, values comprise desires beyond moral principles (i.e., the desirable). Indeed, Schwartz' value definition reflects that what an individual deems desirable is also desired: "Values refer to desirable goals that motivate action. People for whom social order, justice, and helpfulness are important values are motivated to pursue these goals" (Schwartz, 2016, p. 64). However, since cherished values may conflict with each other in certain situations, value priorities are guides to the "best possible living" and serve to solve basic human motivational conflicts in conjunction with the individual's wants and survival needs (Rohan, 2000). In other words, people decide to pursuit certain desirable goals in favor of other, potentially conflicting, similarly desirable goals in order to achieve what they perceive to be the best possible living given their circumstances. Importantly, Rohan argues that people differ in what they perceive to be desirable. This aligns 
with studies showing that some people do not base their moral judgments on Binding foundations (e.g., Graham et al., 2009).

Conversely, moral foundations (and thus moral judgment) may imply more than values (and environmental aspects as described above). For instance, the circular motivational continuum of values may not entirely cover all moral principles (e.g., purity). Furthermore, beyond value motivations, moral judgments in general may comprise motivations to pursue truth and control. As Cornwell and Higgins (2019) stated: "Moral judgments are also about (1) the experience of establishing which norms, values, and beliefs are true or right; and (2) the experience of managing what happens in a social world. The former motivation involves truth or epistemic experiences; the latter involves control experiences" (p. 2). While this is not the inherent function of values, certain values contain the pursuit of truth and control as goals (self-direction and power values). This could additionally contribute to partial convergence.

\subsubsection{Fully Convergent Constructs}

When dimensions share most of their construct-valid variance, constructs can be assumed to be fully convergent. Sverdlik et al. (2012) argued that the values framework fully depicts the spectrum of intra- and cross-cultural moral principles. They pointed out that values with a social focus, namely conservation and self-transcendence values, reflect the moral codes described by the most prominent models on morality, including MFT. Furthermore, values with a personal focus, namely openness to change and self-enhancement values, reflect a violation of these moral codes. Therefore, basic value orientations and moral foundations may underlie the same social versus personal preferences for certain goals and moral principles.

In the context of the present construct theories, we deem full convergence to be most plausible. We base this assertion on their common putative adaptive function, their evaluative nature, and their reported links with "key" constructs. We speculate that basic value orientations and moral foundations may reflect convergent dimensions in terms of two fundamental world beliefs, as discussed by Rohan (2000) and Federico, Weber, Ergun, and Hunt (2013). Conservation and Binding foundations reflect a high level of belief about the world as a dangerous, unpredictable, and threatening place (dangerous world belief), whereas Self-transcendence and Individualizing foundations express a low level of belief about the world as a competitive and ruthless "jungle" (competitive world belief). Specifically, a dangerous world belief may drive the preference for security, structure, and stability, which is expressed in Conservation and Binding foundations, and a competitive world belief may drive 
the preference for individual profit and success (vs. social harmony and support), which is expressed in Self-transcendence and Individualizing foundations.

\subsection{The Present Study}

We sought to investigate the association between value orientations, based on the TBV, and moral foundations, based on MFT. We expected Conservation to fully converge with Binding foundations (Hypothesis 1; H1) and Self-transcendence to fully converge with Individualizing foundations (Hypothesis 2; H2). Full construct convergence entails that a common factor explains more than $50 \%$ of true score variance (i.e., adjusted for residual variance) in both value orientations and moral foundations after taking rater- and dimensionspecific factors into account ( $\mathrm{H} 1 \mathrm{a}$ and $\mathrm{H} 2 \mathrm{a})$. In addition, a common factor fully accounts for the genetic variance in value orientations and moral foundations ( $\mathrm{H} 1 \mathrm{~b}$ and $\mathrm{H} 2 \mathrm{~b}$ ). We tested these hypotheses on the basis of multi-rater and genetically informative data.

Convergent constructs should correlate highly due to a common construct-valid factor. Previous studies often relied on the single method of self-reports. This method can lead to an under- or an overestimation of the strength of a link due to common method variance (Podsakoff, MacKenzie, Lee, \& Podsakoff, 2003). Multitrait-multimethod analyses (Campbell \& Fiske, 1959) can separate the proportion of covariance attributable to method effects from the proportion of shared construct variance (i.e., convergent validity). Combining different rater perspectives, such as self-reports and those from well-informed others, allowed us to partial out unsystematic variance due to error of measurement and variance attributable to rater-specific response tendencies (Eid, Lischetzke, Nussbeck, \& Trierweiler, 2003). Thus, to test for structural convergence, we conducted extended multitrait-multirater analyses. These analyses allowed us to determine whether the dimensions diverge (i.e., a common factor accounts for less variance in both dimensions across raters than dimension- and rater-specific factors do), partially converge (i.e., a common factor accounts for more variance in one dimension across raters than dimension- and rater-specific factors do), or fully converge (i.e., a common factor accounts for more variance in both dimensions across raters than dimensionand rater-specific factors do).

Moreover, genetically informed data illuminate the sources of divergence and convergence. Twin data can help to examine common and unique sources of individual differences in the dimensions by comparing the amount of common and specific genetic and environmental variance. Bivariate twin model analyses enabled us to illuminate whether the constructs diverge (i.e., each dimension shows unique genetic variance), partially converge (i.e., a common factor explains the total genetic variance in at least one dimension), or fully 
converge (i.e., a common factor explains the total genetic variance in both dimensions). Additionally, the model analyses allowed us to explore the role of potential common environmental factors accounting for the association between two dimensions.

\section{Methods}

\subsection{Samples}

We used data from the Study of Personality Architecture and Dynamics (SPeADy), an ongoing longitudinal research project. At the time of data analyses, cross-sectional data were available from the first wave of assessment of two German-speaking samples. The samples were primarily recruited in Germany between January 2016 and January 2018, using diverse procedures (e.g., media announcements, posters and leaflets, contacting twin clubs and sports clubs). One sample consisted of twins and twins' participating parents, offspring, and life partners (twin family study). The other sample consisted of self-raters and informants (age groups study). Respondents were invited to participate either via an online platform or through mailed questionnaires. They completed several measures of personality traits and related motivational and attitudinal characteristics. For details of the SPeADy project, see Kandler, Penner, Richter, and Zapko-Willmes (2019). ${ }^{2}$

From the full SPeADy data set, we extracted data of participants who provided information on at least one measure and for whom self- and informant reports (age groups study) or self-reports of both twins of a pair (twin family study), were available. Both the twin and multi-rater samples were age-heterogeneous (twins: $M=38.84, S D=19.94$, range: $14-86$; nontwin self-raters: $M=39.60, S D=18.06$, range: $14-89$ ) and included a slightly higher proportion of female participants (twins: $73 \%$ female; nontwin self-raters: 66\%). The twin sample included 555 twin pairs $^{3}$ : 218 monozygotic (MZ) twin pairs (168 female and 50 male) and 337 dizygotic (DZ) twin pairs (191 female, 56 male, and 90 opposite-sex pairs). The multi-rater sample $(n=924)$ included respondents who provided a self-report (henceforth the targets) and at least one informant report. We considered only one informant report per target due to our methodological approach (see below) and the relatively small number of targets with multiple informant ratings. For targets rated by more than one informant, we included the informant who completed both measures and reported knowing the target best and at least

\footnotetext{
${ }^{2} \mathrm{SPeADy}$ data are freely available for scientific use on request. See www.speady.de for the request procedure and policies for protecting data privacy. For scripts of the conducted analyses, see https://osf.io/76gzj. This study was not preregistered.

${ }^{3}$ Among these was one set of multizygotic triplets, which we treated as 3 dyadic DZ twin pairs.
} 
fairly well. By and large, informants were relatives (32\%), partners, (31\%), or friends (34\%). Informants had a sex ratio ( $66 \%$ female) and age distribution $(M=38.44, S D=16.65$, range: 14-88) similar to targets. Informants reported knowing the target very well (71\%), well $(26 \%)$, or fairly well $(3 \%)$, and knowing their target on average for 19.13 years $(S D=14.21)$.

\subsection{Measures and Measurement Models}

\subsubsection{Basic Value Orientations}

Participants completed the German version of Schwartz's Refined Portrait Values Questionnaire (Schwartz et al., 2012). Each of 57 items describes a person in terms of his/her values. Participants were instructed to rate the items according to their own or their target's similarity to the portrayed person. Items were rated on a 6-point scale, ranging from 1 (not like me/the target at all) to 6 (very much like me/the target). Tables A1 to A2 in supplement A provide descriptive statistics. In order to confirm the measurement model, we ran hierarchical confirmatory factor analysis (CFA) models with two uncorrelated higher-order value dimensions Conservation and Self-transcendence. We specified 16 value items that should load on each dimension and allowed three values (face, hedonism, humility) to load on both. In addition, all 57 value items loaded on a common factor, representing a rater-specific method factor measuring acquiescence, for example (see Figure 1A for the model). In order to achieve model identification, we fixed factor means to zero and the loading of the item with the highest loading on each latent factor after a first iteration to one.

We ran separate CFAs for each sample and tested metric measurement invariance ${ }^{4}$ with ratings clustered within raters. In other words, we did not compare raters via separate groups, but nested them within target-informant and twin-cotwin dyads. We compared a model with factor loadings constrained to be equal across raters (and twin siblings) to an unconstrained model. The models allowed correspondent higher-order factors (e.g., Conservation based on self- and informant report) to be correlated. Metric measurement invariance is required for the present analyses, as equivalent item loadings are a prerequisite

\footnotetext{
${ }^{4} \mathrm{~A}$ "complete" test for metric measurement invariance is (at present) not possible because metric measurement invariance cannot be distinguished from a "univariate pattern of non-invariance” (e.g., Klößner \& Klopp, 2017; Raykov, Marcoulides, \& Li, 2012). The test only allows us to check whether the ratios between fixed loadings are invariant, not whether factor loadings uniformly differ in strength between groups. However, given the characteristics of the dependent groups we compared (i.e., participants of the same cultural background, comparable age ranges, and most likely comparable cognitive abilities), we deem such uniform loading differences between the tested groups unlikely and assume that our approach is reliable in this regard.
} 
for the computation of latent factor scores and comparison of variance-covariance structures. Models were tested in R 3.4.0 (R Core Team, 2017) using RStudio 1.0.143 (RStudio Team, 2016) and the packages lavaan (Rosseel, 2012), semTools (semTools Contributors, 2016), and psych (Revelle, 2017). Parameters were estimated via maximum likelihood procedures with robust standard errors (Huber-White "sandwich" estimator) and a scaling-corrected $\chi^{2}$ test statistic (asymptotically) analogous to the Yuan-Bentler $\mathrm{T}_{2} *$ test statistic (MLR; Yuan \& Bentler, 2000). For model evaluation, we considered model fit requirements for optimal Type I and Type II error rejection rates (combinational rule of root mean square error of approximation $[$ RMSEA] $<.06$ and standardized root mean square residual $[S R M R]<.09 ; \mathrm{Hu}$ $\&$ Bentler, 1999; Steiger, 1990). ${ }^{5}$

Because the $\chi^{2}$-difference test statistic might lead to falsely rejecting a model, we also considered alternative fit guidelines in the form of changes in $\mathrm{CFI}(\Delta \mathrm{CFI} \leq .01)$ for testing metric measurement invariance (Cheung \& Rensvold, 2002; Little, 2013). The hierarchical CFA models showed a satisfactory fit (RMSEA $=.040$, SRMR $=.063-.064)$. The SatorraBentler scaled $\chi^{2}$-difference test (Bryant \& Satorra, 2012; Satorra \& Bentler, 2001) indicated that the fit of the constrained model was not significantly worse than the unconstrained model for the twin sample $\left(\Delta \chi^{2} \mathrm{SB}=106.28, \Delta d f=114, p=.684\right)$. This was not the case for the multirater sample $\left(\Delta \chi^{2} \mathrm{SB}=188.66, \Delta d f=114, p<.001\right)$. However, the alternative fit index $(\Delta \mathrm{CFI}=$ .00) supported metric measurement invariance for this sample as well. Tables B1 to B2 of supplement B provide model fit statistics (including $\chi^{2}$-test statistics) and parameter estimates.

${ }^{5}$ Following a rule of thumb proposed by Kenny, we do not report incremental fit indices for the CFA models because the RMSEA of all baseline models of basic value orientations and of two baseline models of moral foundation dimensions was $<.158$ (see http://davidakenny.net/cm/fit.htm). 


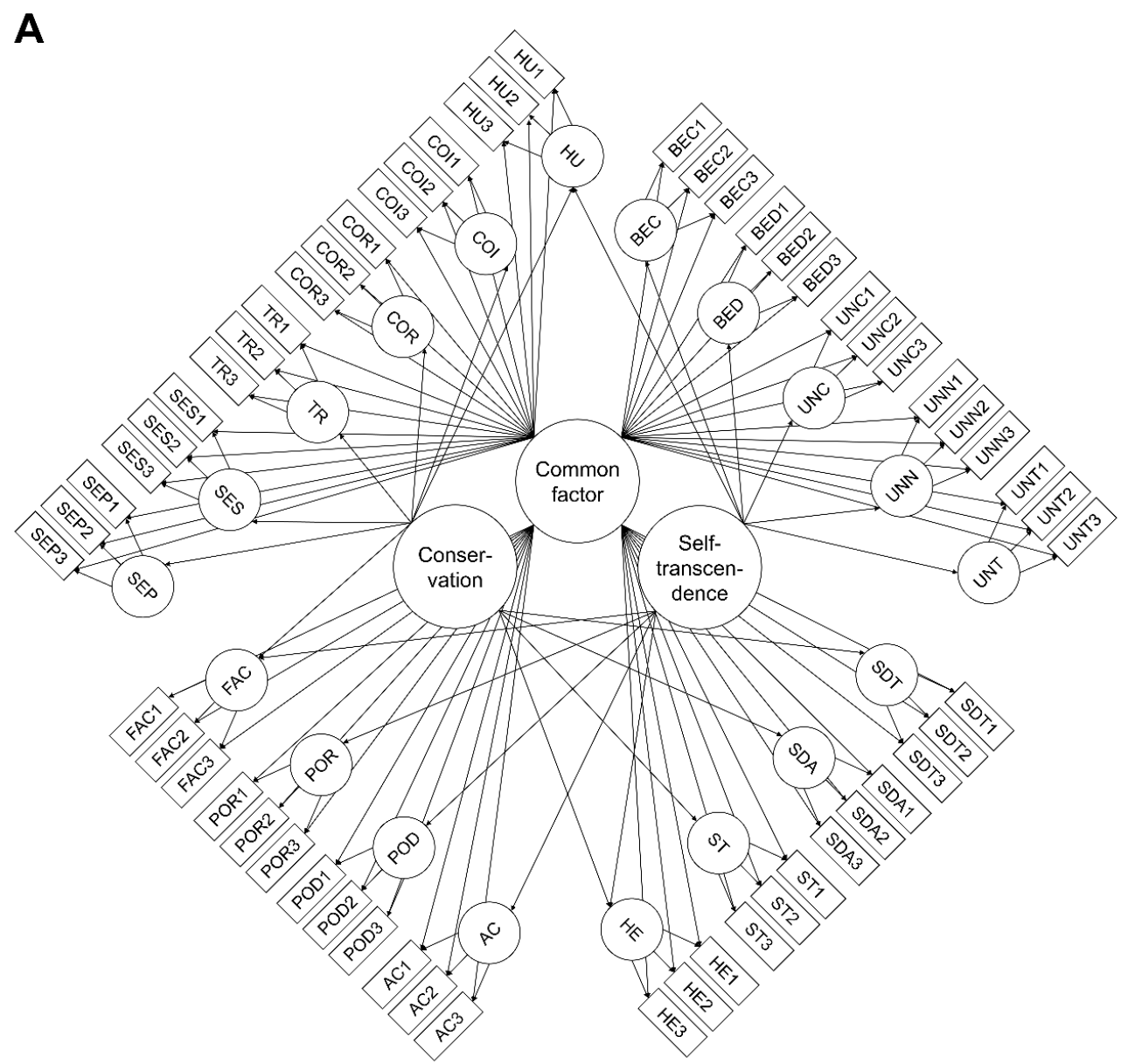

B

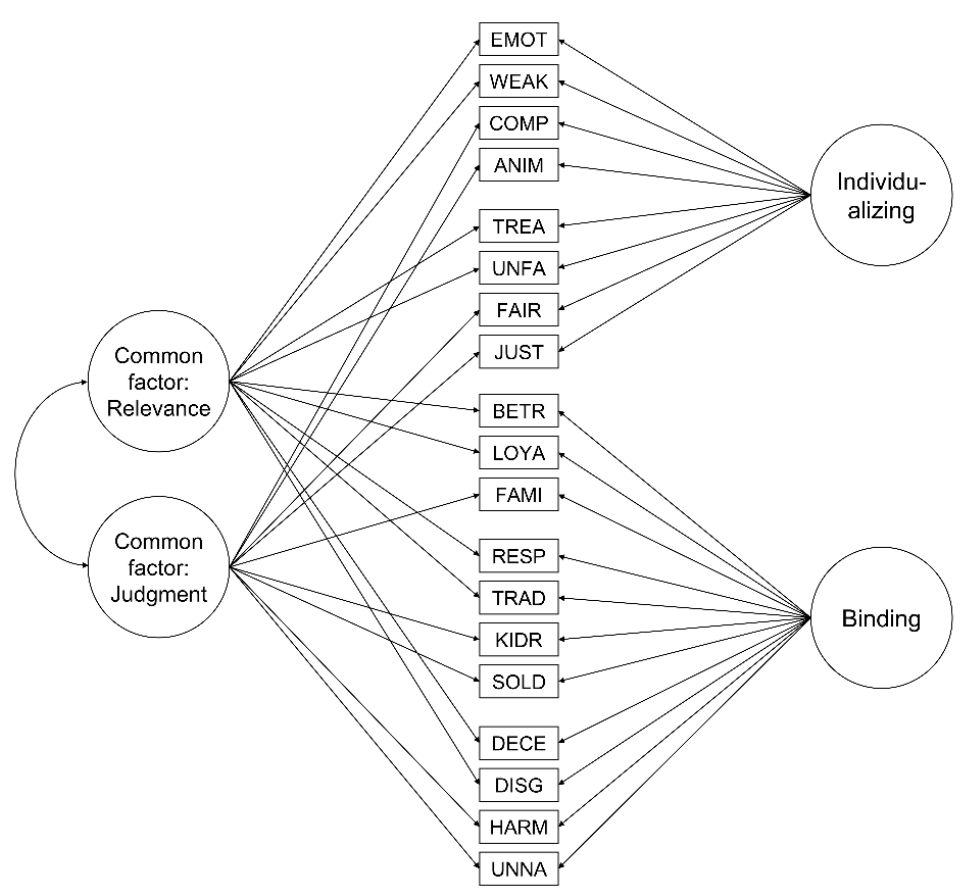

Figure 1. Hierarchical confirmatory factor analysis models of (A) higher-order value orientations and (B) moral foundations. For simplicity, residual factors and path labels are not shown. See text for model descriptions. 


\subsubsection{Moral Foundations}

The individual's endorsement of moral foundations (Haidt, Graham, \& Joseph, 2009) was measured with a German short version of the Moral Foundations Questionnaire (retrieved from www.moralfoundations.org/questionnaires; Graham et al., 2011). The questionnaire consisted of two subscales of 10 items: A relevance subscale measured the relevance targets ascribed to various moral foundations when evaluating (im-)morality. A judgment subscale measured the target's agreement with contextualized statements pertaining to moral foundations. Items were rated on a 6-point scale, ranging from 1 (not at all relevant/strongly disagree) to 6 (extremely relevant/strongly agree). We replaced two loyalty (vs. betrayal) items and one authority (vs. subversion) item with items from the full questionnaire version ${ }^{6}$ because these items had small correlations with the other items of the same foundation in a preliminary data analysis in a German sample (Joeckel, Bowman, \& Dogruel, 2012). ${ }^{7}$ Moreover, we replaced one loyalty item whose historical connotations were particularly socially undesirable for German participants. ${ }^{8}$ For item wording, see the above URL. Tables A3 and A4 of supplement A provide descriptive statistics.

Similar to the procedure for value orientations outlined above, we ran hierarchical CFAs with two uncorrelated higher-order factors, Binding foundations and Individualizing foundations. We allowed five moral foundations to load on either. In addition, because one common (method) factor yielded partially nonsignificant loadings, we included two correlated common method factors, with items of each subscale (relevance and judgment) loading on their respective method factor (see left-hand side of Figure 1B). In order to achieve model identification, we fixed factor means to zero and the parameter with the highest loading on the respective latent factor to one (after a first iteration with one random fixation). The analyses yielded negative variance estimates of care (Heywood cases). To identify a potential model misidentification due to item cross-loadings, we subsequently inspected inter-item, item-foundation, and subscale correlations (see Tables B3 and B4 in

\footnotetext{
6"Whether or not someone's action showed love for his or her country" was replaced by "Whether or not someone showed a lack of loyalty", and "Men and women each have different roles to play in society" was replaced by "If I were a soldier and disagreed with my commanding officer's orders, I would obey anyway because that is my duty".

${ }^{7}$ We thank Nick Bowman and Sven Joeckel for providing data for the preliminary analyses from the cited study. "I am proud of my country's history" was replaced by "It is more important to be a team player than to express oneself".
} 
Supplement B). The correlations revealed that (1) several items similarly correlated with items of the same and of a related foundation (e.g., a harm item showing equal correlations with other harm and fairness items), and (2) one loyalty item showed similar correlations across all foundations. Due to this, we ran non-hierarchical confirmatory factor analyses, excluding the loyalty item (see Figure 1B). Model fit results met the aforementioned criteria $(\mathrm{RMSEA}=.052-.057, \mathrm{SRMR}=.058-.059)$. The models supported metric measurement invariance, because their fit did not deteriorate significantly when factor loadings were fixed across dependent dyads (twin: $\Delta \chi^{2} \mathrm{SB}=12.02, \Delta d f=34, p>.999$; multi-rater: $\Delta \chi^{2} \mathrm{SB}=27.15$, $\Delta d f=34, p=.792)$. Tables B1 and B5 in Supplement B provide model estimates and model fit statistics.

\subsubsection{Latent Factor Scores}

To obtain individual scores on the value and moral foundation dimensions, we computed latent factor scores. We used the partial least squares regression method (Thomson, 1934; Thurstone, 1935) based on the conducted CFAs for non-nested data (i.e., assuming metric measurement invariance). By including common method factors, factor scores represented quasi-ipsatized values. That is, variance due to response tendencies (e.g., acquiescence, central tendency bias) could be partialed out (He \& van de Vijver, 2015). Thus, this approach allowed us to reduce unsystematic error variance and to disentangle systematic method variance shared by all items (of the same scale) from the factor score variance. Importantly, past literature suggested that this common method factor could also include construct-valid variance (Borg \& Bardi, 2016). However, we do not think that this approach biased our results, since this procedure removes mean differences in related dimensions that are not the focus of this study, such as differences in a general value- and moral-guidedness. On the contrary, we deem it vital to remove this common method factor in order to avoid a higher dimension covariance due to social desirability (Danioni \& Barni, 2020) that can be common across rater perspectives (Roth \& Altmann, 2019). In short, it increases the reliability of the convergence estimation.

The factor scores of value orientations and moral foundations can be interpreted as follows: The sign of the score indicates the individual orientation towards either higher-order value and the absolute value of the score indicates the extent to which the individual gives priority to the respective higher-order value. For Self-transcendence, a positive score indicates a preference for self-transcendence whereas a negative score indicates a preference for self-enhancement. Similarly, a positive Individualizing foundations score, represents 
strong use of individualizing foundations whereas a negative score represents weak to nonuse of Individualizing foundations. A positive score for Conservation indicates a preference for conservation whereas a negative score indicates a preference for openness to change. Analogously, a positive score for Binding foundations indicates strong use of Binding foundations whereas a negative score indicates weak to nonuse of Binding foundations. With $M=0$ for all dimensions, variance was comparable across all dimensions (Conservation: $S D$ $=0.62-0.71$; Self-transcendence: $S D=0.82-0.84$; Binding foundations: $S D=0.82-0.95$ ) but Individualizing foundations $(S D=0.38-0.43)$.

Table 1 shows self-other agreements and twin correlations. Table 2 displays zeroorder (within-rater) correlations between value orientations and moral foundations. Supplement D provides multiple regression analyses of age and sex effects and a comparison of age trends across sexes. For interested readers, we additionally provide all main analyses using (manifest) mean scores in Supplement F. 
Table 1. Self-Other and Twin Correlations

\begin{tabular}{|c|c|c|c|c|c|c|c|c|c|c|}
\hline \multirow[b]{2}{*}{ Dyad } & \multicolumn{4}{|c|}{ Value orientation } & \multicolumn{4}{|c|}{ Moral foundations } & \multicolumn{2}{|c|}{ Steiger's Z-test } \\
\hline & $n$ & $r$ & $95 \% \mathrm{Cl}$ & $p$ & $n$ & $r$ & $95 \% \mathrm{Cl}$ & $p$ & $z$ & $p$ \\
\hline & & \multicolumn{3}{|c|}{ Conservation } & \multicolumn{4}{|c|}{ Binding foundations } & & \\
\hline Self-other & 924 & .56 & {$[.51, .60]$} & $<.001$ & 924 & .51 & {$[.46, .55]$} & $<.001$ & 1.81 & .070 \\
\hline MZ twins & 218 & .62 & {$[.54, .70]$} & $<.001$ & 218 & .43 & {$[.31, .53]$} & $<.001$ & 3.07 & .002 \\
\hline DZ twins & 337 & .26 & {$[.16, .36]$} & $<.001$ & 337 & .29 & {$[.18, .38]$} & $<.001$ & -0.34 & .735 \\
\hline same-sex & 247 & .29 & {$[17, .40]$} & $<.001$ & 247 & .31 & {$[.20, .42]$} & $<.001$ & -0.35 & .730 \\
\hline \multirow[t]{2}{*}{ opposite-sex } & 90 & .18 & {$[-.02, .38]$} & .084 & 90 & .22 & {$[.02, .41]$} & .036 & -0.28 & .778 \\
\hline & \multicolumn{4}{|c|}{$\underline{\text { Self-transcendence }}$} & \multicolumn{4}{|c|}{$\underline{\text { Individualizing foundations }}$} & & \\
\hline Self-other & 924 & .46 & {$[.41, .51]$} & $<.001$ & 924 & .30 & {$[.24, .35]$} & $<.001$ & 4.46 & $<.001$ \\
\hline MZ twins & 218 & .46 & {$[.35, .56]$} & $<.001$ & 218 & .38 & {$[.27, .49]$} & $<.001$ & 0.99 & .324 \\
\hline DZ twins & 337 & .26 & {$[.15, .35]$} & $<.001$ & 337 & .14 & {$[.03, .24]$} & .011 & -1.68 & .093 \\
\hline same-sex & 247 & .35 & {$[.23, .45]$} & $<.001$ & 247 & .19 & {$[.07, .31]$} & .002 & 1.93 & .054 \\
\hline opposite-sex & 90 & .05 & {$[-.16, .26]$} & .620 & 90 & -.03 & {$[-.23, .18]$} & .784 & 0.56 & .575 \\
\hline
\end{tabular}

Note. Twin pair correlations are based on CFA-based factor scores (see Figure 1) corrected for age and sex effects as found by the reported multiple regression models. Correlations between same-sex DZ and opposite-sex twins did not significantly differ for Conservation $(z=0.93, p$ $=.350)$, Binding foundations $(z=0.78, p=.438)$, and Individualizing foundations $(z=1.78, p=.075)$, but for Self-transcendence $(z=2.53, p=$ .012). 
Table 2. Zero-order (Within-Rater) Correlations Between Value Orientations and Moral Foundations

\begin{tabular}{|c|c|c|c|c|c|c|c|}
\hline \multirow{2}{*}{$\begin{array}{l}\text { Moral } \\
\text { foundations }\end{array}$} & \multirow[b]{2}{*}{ Subsample } & \multicolumn{3}{|c|}{ Conservation } & \multicolumn{3}{|c|}{ Self-transcendence } \\
\hline & & $r$ & $95 \% \mathrm{Cl}$ & $p$ & $r$ & $95 \% \mathrm{Cl}$ & $p$ \\
\hline \multirow[t]{4}{*}{ Binding } & Twins & .49 & {$[.44, .53]$} & $<.001$ & -.15 & {$[-.21,-.10]$} & $<.001$ \\
\hline & Twins (res.) & .44 & {$[.39, .49]$} & $<.001$ & -.23 & {$[-.29,-.17]$} & $<.001$ \\
\hline & Targets & .62 & {$[.58, .66]$} & $<.001$ & -.22 & {$[-.28,-.16]$} & $<.001$ \\
\hline & Informants & .60 & {$[.56, .64]$} & $<.001$ & -.26 & {$[-.32,-.20]$} & $<.001$ \\
\hline \multirow[t]{4}{*}{ Individualizing } & Twins & .08 & {$[.02, .14]$} & .006 & .31 & {$[.25, .36]$} & $<.001$ \\
\hline & Twins (res.) & .08 & {$[.02, .14]$} & .007 & .30 & {$[.24, .35]$} & $<.001$ \\
\hline & Targets & .00 & {$[-.06, .07]$} & .945 & .33 & {$[.27, .39]$} & $<.001$ \\
\hline & Informants & .03 & {$[-.03, .10]$} & .339 & .47 & {$[.42, .52]$} & $<.001$ \\
\hline
\end{tabular}

Note (res.) $=$ residual factor scores, corrected for age and sex effects. Correlations $\geq .40$ are bold-faced. 


\section{Analyses \& Results}

We used R/RStudio and the package lavaan for the multitrait-multirater models and IBM SPSS Amos 24.0.0 for the twin models (Arbuckle, 2016). The model parameter estimates were derived with MLR for all analyses in $\mathrm{R}$ and maximum likelihood estimation procedures in Amos. We applied the same model fit criteria as already introduced for the CFAs. Nested models were compared using the $\chi^{2}$-difference test. Non-nested models were descriptively compared using RMSEA, comparative fit index (CFI), and expected crossvalidation index (ECVI; Browne \& Cudeck, 1993). A smaller RMSEA and ECVI and a larger CFI indicated superior model fit.

\subsection{Multitrait-Multirater Analyses}

Convergent constructs should show a common structural basis (i.e., a common latent factor) across different methodological approaches. In order to identify the amount of common variance, we performed extended multitrait-multirater (MTMR) analyses using structural equation modeling of the individual factor scores based on self- and informant reports (see Figure 2). MTMR analyses permit differentiating construct-valid variance as evidenced across methods from method variance across traits. This enabled us to avoid misjudging within-method correlations between two variables as evidence for dimensional convergence. It also enabled us to compare the amount of convergent variance components with the amount of rater-specific (method) variance components.

In addition, we sought to discriminate the variance specific to each value orientation or moral foundation. This variance - in the following called dimension-specific - may reflect instrument-specific factors due to the measurement instrument (PVQ and MFQ) and construct-specific factors. However, the modeled factors specific to the value orientations and moral foundations should largely account for dimension-specific variance, because the common method factors we had included in the CFA-based procedure to compute factor scores would have largely partialed out instrument-specific variance. Consequently, we could compare common factor variance with rater- and dimension-specific variance components. The full MTMR model depicted in Figure 2 included nine latent factors: one common factor, two method (or rater-specific) factors for self- and informant assessments, two dimensionspecific factors for the respective value and moral foundation dimension, and four residual (or error) components. All path coefficients were fixed to one and factor means were set to zero in order to identify factor variances (with $d f=1$ ). To test for more parsimonious models, we compared the full model sequentially with a model (1) without either and both dimension- 
specific factors, (2) without either and both method factors, and (3) without a common factor. See Figure $\mathrm{C} 1$ in Supplement $\mathrm{C}$ for an illustration of the model fitting procedure. A significant and comparably larger amount of common factor variance in the presence of the other components would indicate that the dimensions of value orientations and moral foundations converge (in line with $\mathrm{H} 1 \mathrm{a}$ and $\mathrm{H} 2 \mathrm{a}$ ).

\subsubsection{Conservation and Binding Foundations}

A model without the Conservation-specific factor yielded the best fit (see Table 3). For standardized path coefficients, see Figure 3. The common factor accounted for the largest proportion of true score variance in self- and informant-reports on Conservation (61-73\%), which was comparably larger than for Binding foundation (43-48\%). Rater specificity explained a moderate proportion of true score variance in Binding foundation (18-27\%) and Conservation (27-39\%). Dimension specificity moderately contributed to true score variance in Binding foundation (30-34\%). Although a common factor explained a substantial proportion of true-score variance in both dimensions, the overlap did not reach the criterion of $50 \%$ in the Binding. This finding indicated that Conservation and Binding only partially converged on a structural basis, not confirming H1a.

\subsubsection{Self-transcendence and Individualizing Foundations}

A model without the Individualizing-specific factor showed the best model fit (see Table 4). See Figure 4 for the model including standardized path coefficients. True score variance in Self-transcendence was primarily dimension-specific (59-72\%), with small to moderate components accounted for by the common factor (14-17\%) and rater specificity $(11-27 \%)$. The common factor explained comparably more true score variance in self- and informant reports of Individualizing foundations (34-60\%). Rater specificity substantially explained variance in informant reports of Individualizing foundations scores (66\%) and to a lesser extent for self-reports (40\%). Notably, the analyses yielded considerable proportions of residual variance in Self-transcendence and self-reports on Individualizing foundations. These results did not support $\mathrm{H} 2 \mathrm{a}$, instead suggesting construct divergence. 


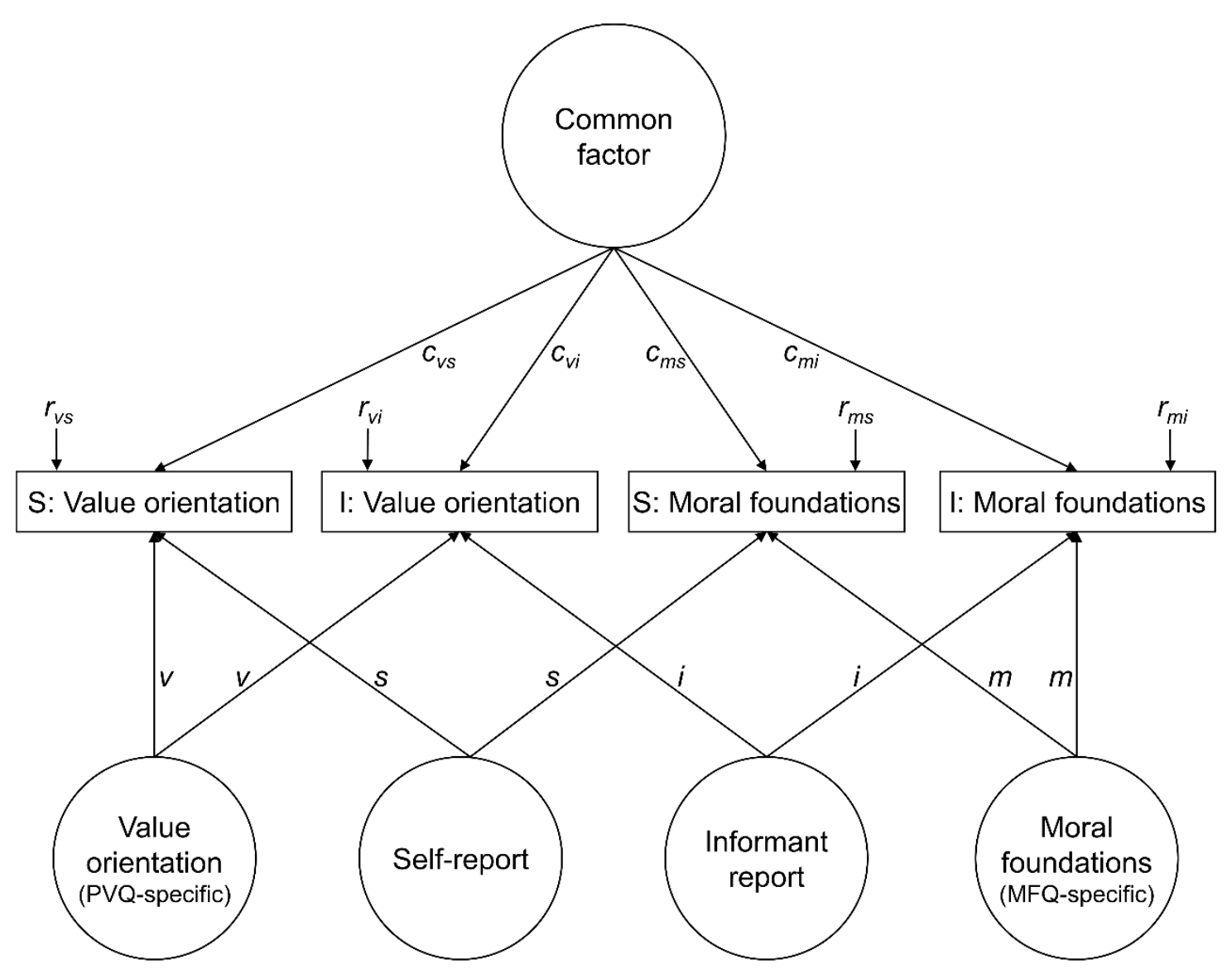

Figure 2. Multitrait-multirater model, including each target and informant report on a basic value orientation and moral foundation dimension. $\mathrm{S}=$ self-report; $\mathrm{I}=$ informant report; Value orientation (PVQ-specific)/Moral foundations (MFQ-specific) $=$ dimension-specific factors; Self-report/Informant report $=$ method factors; $c_{v s} / c_{v i} / c_{m s} / c_{m i}=$ factor loadings on the common factor; $v / m=$ factor loadings on value-specific and moral-specific factors. $s / i=$ factor loadings on method-specific factors; $r_{v s} / r_{v i} / r_{m s} / r_{m i}=$ residual variance components. 
Table 3. MTMR Model Comparisons for Conservation and Binding Foundations

\begin{tabular}{|c|c|c|c|c|c|c|c|c|c|c|c|}
\hline Model & $X^{2}$ robust & df & $p$ & CFI & RMSEA [90\% Cl] & SRMR & ECVI & Comp. & $\Delta \mathrm{X}^{2}$ & $\Delta \mathrm{df}$ & $p$ \\
\hline 1: Full* & 0.961 & 1 & .327 & 1.00 & $.000[.000, .000]$ & .007 & .029 & & & & \\
\hline 2a: No Conservation factor & 2.388 & 2 & .303 & 1.00 & $.014[.000, .070]$ & .015 & .028 & 1 & 1.412 & 1 & .235 \\
\hline 2b: No Binding factor & 98.408 & 2 & $<.001$ & .92 & $.228[.191, .268]$ & .074 & .130 & 1 & 92.828 & 1 & $<.001$ \\
\hline 2: No dimension-specific factors & 103.263 & 3 & $<.001$ & .91 & $.190[.160, .222]$ & .063 & .137 & 1 & 98.589 & 2 & $<.001$ \\
\hline 3a: No self-report factor ${ }^{*}$ & 92.952 & 2 & $<.001$ & .92 & $.222[.185, .261]$ & .108 & .129 & 1 & 84.708 & 1 & $<.001$ \\
\hline 3b: No informant report factor ${ }^{*}$ & 37.360 & 2 & $<.001$ & .97 & $.138[.100, .180]$ & .703 & .064 & 1 & 36.379 & 1 & $<.001$ \\
\hline 3: No method factors ${ }^{*}$ & 168.226 & 3 & $<.001$ & .85 & $.244[.215, .275]$ & .056 & .220 & 1 & 156.880 & 2 & $<.001$ \\
\hline 4: No common factor* & 289.877 & 2 & $<.001$ & .88 & $.395[.357, .434]$ & .210 & .339 & 1 & 271.110 & 1 & $<.001$ \\
\hline
\end{tabular}

Note. Comp. = compared with model.

* The model yielded a small negative residual variance of the latent Conservation factor (Heywood case). 


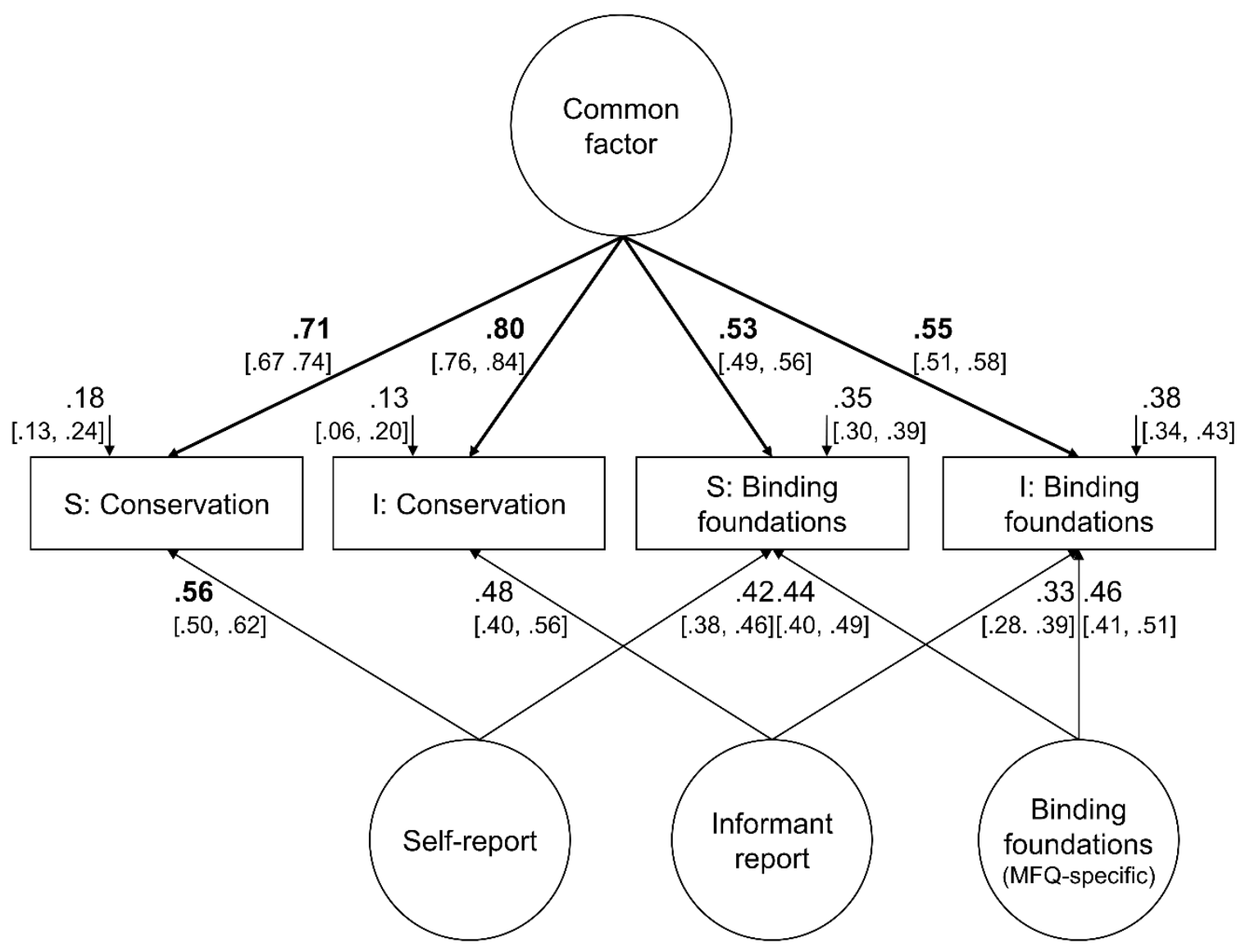

Figure 3. Multitrait-multirater model analysis results of Conservation and Binding foundations. Path coefficients are standardized. All path coefficients $\geq .50$ and the strongest paths for each manifest variable are bold-faced. Confidence intervals (95\%) based on robust standard errors are shown in brackets. 
Table 4. MTMR Model Comparisons for Self-transcendence and Individualizing Foundations

\begin{tabular}{|c|c|c|c|c|c|c|c|c|c|c|c|}
\hline Model & $X^{2}$ robust & $\mathrm{df}$ & $p$ & CFI & RMSEA [90\% Cl] & SRMR & ECVI & Comp. & $\Delta \mathrm{X}^{2}$ & $\Delta \mathrm{df}$ & $p$ \\
\hline 1: Full ${ }^{\star}$ & 0.035 & 1 & .852 & 1.00 & $.000[.000, .045]$ & .002 & .028 & & & & \\
\hline 2a: No Self-transcendence factor ${ }^{*}$ & 139.386 & 2 & $<.001$ & .72 & $.273[.239, .308]$ & .101 & .208 & 1 & 124.500 & 1 & $<.001$ \\
\hline 2b: No Individualizing factor & 12.345 & 2 & .002 & .98 & $.075[.041, .114]$ & .041 & .042 & 1 & 11.244 & 1 & $<.001$ \\
\hline 2: No dimension-specific factors & 144.190 & 3 & $<.001$ & .72 & $.226[.198, .255]$ & .108 & .209 & 1 & 136.810 & 1 & $<.001$ \\
\hline 3a: No self-report factor ${ }^{*}$ & 7.020 & 2 & .030 & .99 & $.052[.015, .095]$ & .024 & .034 & 1 & 6.996 & 1 & .008 \\
\hline 3b: No informant report factor ${ }^{*}$ & 502.548 & 2 & $<.001$ & .87 & $.190[.156, .226]$ & .073 & .117 & 1 & 60.880 & 1 & $<.001$ \\
\hline 3: No method factors* & 79.221 & 3 & $<.001$ & .85 & $.166[.138, .196]$ & .062 & .126 & 1 & 75.154 & 2 & $<.001$ \\
\hline 4: No common factor & 75.587 & 2 & $<.001$ & .85 & $.200[.165, .236]$ & .108 & .123 & 1 & 68.491 & 1 & $<.001$ \\
\hline
\end{tabular}

Note. Comp. = compared with model.

* The model yielded a small negative residual variance of the latent Individualizing foundations factor (Heywood case). 


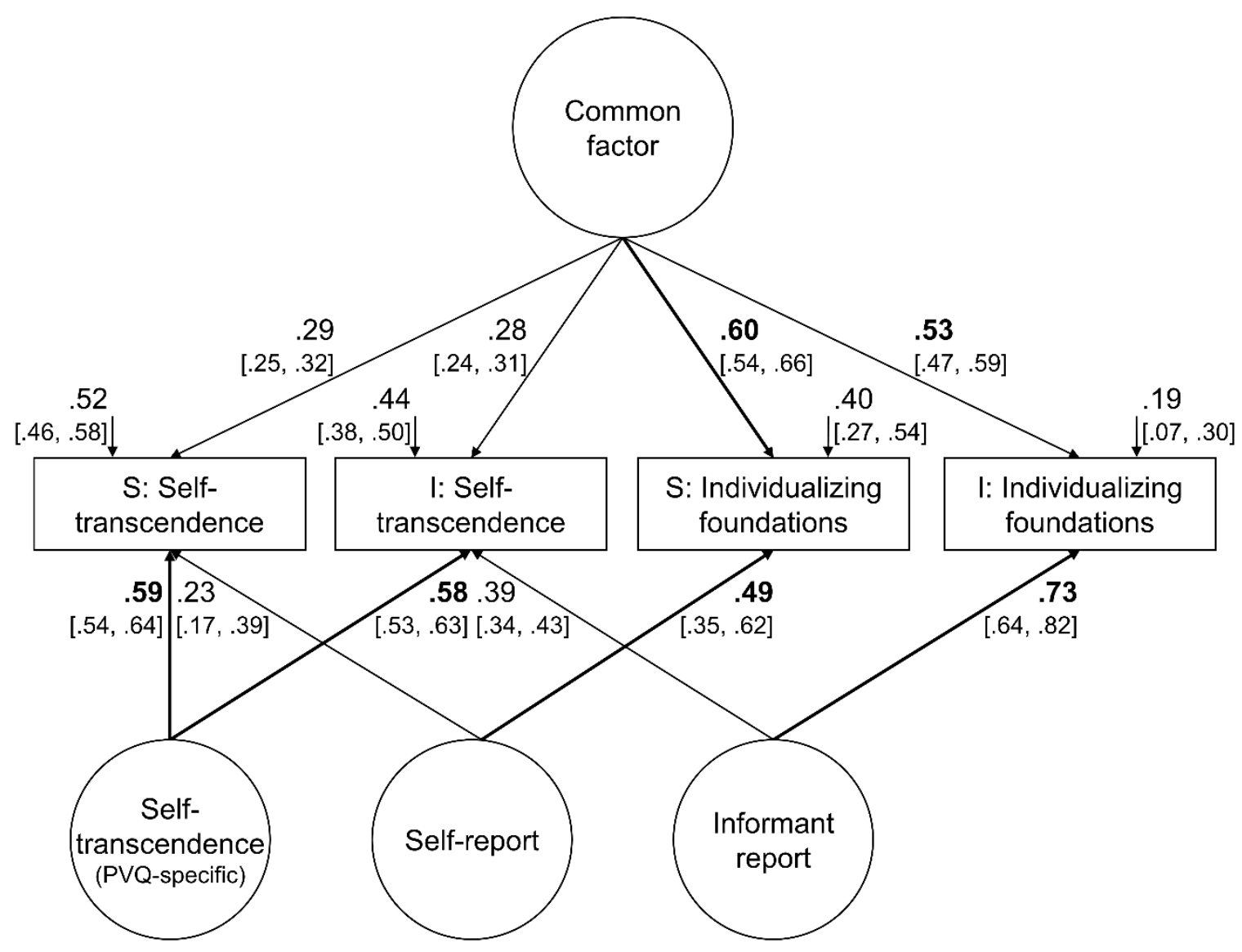

Figure 4. Multitrait-multirater model analysis results of Self-transcendence and Individualizing foundations. Path coefficients are standardized. All path coefficients $\geq .50$ and the strongest paths for each manifest variable are bold-faced. Confidence intervals (95\%) based on robust standard errors are shown in brackets. 


\subsection{Bivariate Twin Model Analyses}

In line with the hypothesis of dimensions' convergence, a common genetic factor should fully account for the genetic variance in both dimensions ( $\mathrm{H} 1 \mathrm{~b}$ and $\mathrm{H} 2 \mathrm{~b}$ ). In addition, common environmental sources (e.g., due to shared social factors) could additionally account for the link between dimensions. To identify the genetic and environmental covariance of the dimensions, we ran bivariate twin model analyses. The analysis of differences within and between twin pairs reared together allows estimations of genetic and environmental sources of the variance in a variable and of the covariance between two variables. MZ and DZ twins differ in their genetic relatedness: MZ twins are genetically identical, whereas fraternal twins share on average $50 \%$ of their segregating genes. We assume that twin pairs reared together, whether they are MZ or DZ twins, share the same environmental influences on their dispositions. Therefore, differences between the correlations of MZ vs. DZ twin pairs are attributable to additive genetic sources $(A)$. If the correlation between MZ twin pairs exceed twice the size of the DZ twin pair correlation, these differences are attributable to nonadditive (i.e., dominance) genetic effects $(D)$. Small differences between $\mathrm{MZ}$ and $\mathrm{DZ}$ twin pair correlations (beyond chance) suggest that crucial environmental sources twins share $(C)$ increase both $\mathrm{MZ}$ and DZ twin similarity. Because $\mathrm{MZ}$ twin siblings share their entire genetic make-up, differences between MZ twin siblings inevitably originate from environmental sources not shared by twins ( $E$, including random error). Following this logic, structural equation models in the form of bivariate twin models enable us to disentangle the variance components that are common and specific to the two variables. Since the twin correlations suggested different models across variables (an $A C E$ model for Binding foundations and Selftranscendence and an $A D E$ model for Conservation and Individualizing foundations), we chose an $A E$ model allowing additionally for specific $C$ and $D$ components (see Figure 5). See Figure E1 in Supplement E for power analyses.

Note that the twin model approach we used relies on the further assumptions that gene-environment correlations and gene $\times$ environment interactions are absent. Thus, the twin model can only estimate the net contributions of genetic and environmental sources that can transact and interact in very complex ways (Bleidorn, Kandler, \& Caspi, 2014; Briley, Livengood, \& Derringer, 2018; Kandler \& Zapko-Willmes, 2017). 


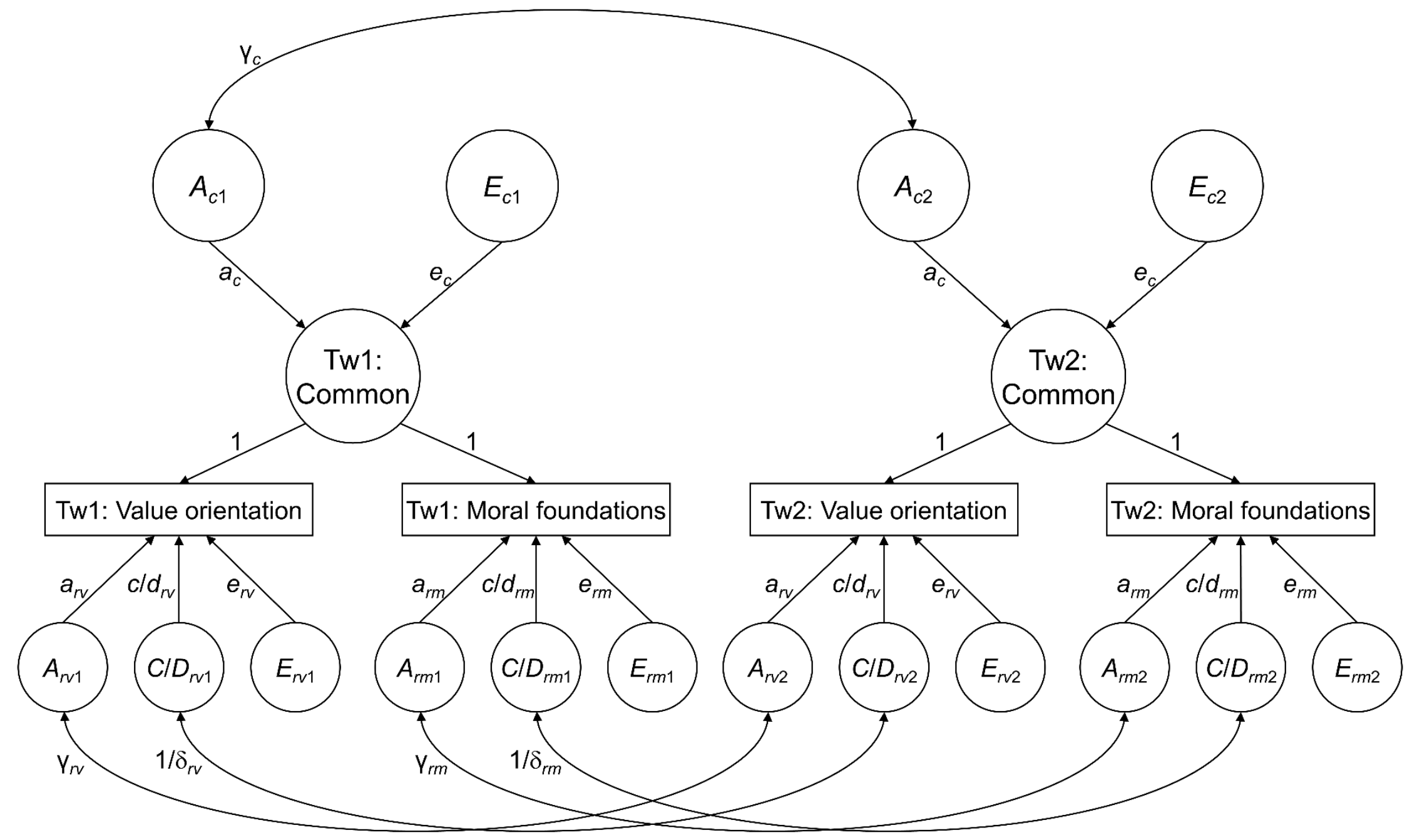


Figure 5. Full bivariate twin model, comprising the basic value orientation and moral foundation dimensions of twin 1 (Tw1) and twin 2 (Tw2). This common pathway model includes a common factor contributing to the variance in both dimensions and mediating common genetic and environmental sources. $\gamma_{c / r v / r m}=$ additive genetic correlation between twins for the common factor/the specific factor of reported value orientation/moral foundation dimension; $\delta_{r v / r m}=$ nonadditive genetic correlation between twins for the specific factor of reported value orientations/moral foundations dimension; $A_{c 1 / 2} / E_{c 1 / 2}=$ Additive genetic/nonshared environmental sources of variance in the common factor of twin $1 / 2 ; a_{c} / e_{c}=$ Additive genetic/nonshared environmental effects on the common factor; $A_{r v 1 / 2} / C / D_{r v 1 / 2} / E_{r v 1 / 2}=$ Additive genetic/shared environmental/nonadditive genetic/nonshared environmental sources of variance specific to the value orientation of twin 1/2;

$A_{r m 1 / 2} / C / D_{r m 1 / 2} / E_{r m 1 / 2}=$ Additive genetic/shared environmental/nonadditive genetic/nonshared environmental sources of variance specific to the moral foundations of twin $1 / 2 ; a_{r v} / c / d_{r v} / e_{r v}=$ Additive genetic/shared environmental/nonadditive genetic/nonshared environmental effects specific to the value orientation; $a_{r m} / c / d_{r m} / e_{r m}=$ Additive genetic/shared environmental/nonadditive genetic/nonshared environmental effects specific to the moral foundations. 
Age and sex effects may increase or decrease estimates of twin similarity and thus the estimates of genetic and environmental variance components (McGue \& Bouchard, 1984). We therefore calculated unstandardized residual scores for value orientation and moral foundation dimensions based on the best fitting regression models of age and sex effects (see Supplement D).

Due to significantly different correlations between DZ same-sex and opposite-sex twins for Self-transcendence (see Table 1), we conducted multivariate sex-limitation model analyses. These allowed us to test for quantitative and qualitative sex differences. Model comparisons showed that a model implying homogeneity fit the data best (see Supplement E, Table E1), indicating no sex differences regarding the amount and nature of genetic and environmental sources of variance.

In addition, nonrandom mating between individuals of similar heritable phenotypes (assortative mating) might act to increase the genetic relatedness of their offspring. Assuming an average proportion of $50 \%$ of shared segregating genes between DZ twin siblings (as would be the case under random mating of twins' parents) would then result in an underestimation of the differences between $\mathrm{MZ}$ and $\mathrm{DZ}$ twin pair correlations. As a consequence, the genetic component would be underestimated and shared environmental sources on twin pair similarity would be overestimated. We were able to take assortative mating of the twins' parents into account and adjust the genetic correlation between DZ twins because data of some twins' parents were available in the SPeADy data. Parents' scores were significantly correlated for Conservation $(r=.39, p<.001)$ and Binding foundations $(r=.43$, $p<.001)$. So we corrected the genetic correlation of DZ twins $(\gamma)$ based on the estimated heritability $\left[h^{2}=2 \times\left(r_{\mathrm{MZ}}-r_{\mathrm{DZ}}\right)\right]$ and spouse similarity ( $\mu$; Martin et al., 1986; Stieger, Kandler, Tran, Pietschnig, \& Voracek, 2017): $0.5+0.5 \times h^{2} \times \mu=0.5+0.5 \times .72 \times .39=$ 0.64 for Conservation, and $0.5+0.5 \times .28 \times .43=0.56$ for Binding foundations. We used the averaged correction, $\gamma_{c}=.60$, for the genetic correlation of the common factor in the common pathway model (see the following section). For Self-transcendence and Individualizing foundations, parents' scores were not significantly correlated $(r=.17, p=.114$, and $r=.03, p$ $=.801)$, thus a correction was not necessary and the genetic correlation remained at $\gamma=.50$ for DZ twins.

We ran common pathway model analyses to disentangle genetic and environmental variance components shared by and specific to value orientation and moral foundation dimensions (see Figure 5). The model consists of a common factor mediating the common genetic and environmental variance components of the linked value and moral foundation 
dimensions in addition to variance components unique to both dimensions. We started with the full model (depicted in Figure 5) and subsequently removed nonsignificant paths to achieve the most parsimonious model whose model fit was not significantly worse than the full model, and the less parsimonious model (see Table 5 for the model comparisons). For genetic and environmental correlations, see Table E2 in Supplement E.

\subsubsection{Conservation and Binding Foundations}

The most parsimonious model was a model without a specific $A$ component for Conservation and $C$ component for Binding foundations. The model fit was satisfactory (see Table 5). Figure 6A presents the standardized path coefficients of the model (see Table E3 in Supplement E for full and parsimonious model statistics). Variance in Conservation was primarily genetic with additive genetic factors accounting for $36 \%$ and nonadditive genetic factors accounting for $27 \%$ of the variance (i.e., heritability $h^{2}=.63$ ). whereas the remaining variance was due to environmental sources of variance (37\%). In contrast, additive genetic factors (46\%) and nonshared environmental factors (54\%) almost equally contributed to the variance in Binding foundations. A common factor explained a proportion of $50 \%$ of Conservation variance and 39\% of Binding foundations variance. Common factor variance was attributable primarily to additive genetic factors $(71 \%)$, followed by unique environmental influences (29\%). The model results yielded moderate but significant genetic effects unique to both dimensions. This finding contradicts H1b, and, consequently, H1.

\subsubsection{Self-transcendence and Individualizing Foundations}

The most parsimonious model did not comprise a specific $A$ and $D$ component of Individualizing foundations and a $C$ component of Self-transcendence. The model fit was satisfactory (see Table 5). Figure 6B depicts the standardized path coefficients (see Table E4 in Supplement E for the full and parsimonious model statistics). Additive genetic (49\%) and nonshared environmental (51\%) sources similarly accounted for variance in Selftranscendence. Nonshared environmental sources mostly accounted for variance in Individualizing foundations (64\%), whereas the remaining variance was due to additive genetic sources $(36 \%)$. The common factor accounted for a small proportion of variance in Self-transcendence (16\%) and more than half of the variance in Individualizing foundations $(59 \%)$ including the complete genetic variance in Individualizing foundations. Common factor variance was primarily attributable to additive genetic factors $(60 \%)$. Since the model analyses suggested a significant genetic component of Self-transcendence not common with 
Individualizing, only partial genetic convergence could be assumed. Thus, $\mathrm{H} 2 \mathrm{~b}$ and consequently $\mathrm{H} 2$ were not confirmed. 


\section{Table 5. Twin Model Comparisons}

\begin{tabular}{|c|c|c|c|c|c|c|c|c|c|c|c|}
\hline Model & $x^{2}$ & df & $p$ & $\mathrm{CFI}$ & RMSEA [90\% Cl] & SRMR & ECVI & Comp. & $\Delta x^{2}$ & $\Delta \mathrm{df}$ & $p$ \\
\hline \multicolumn{12}{|c|}{ Conservation (CO) and Binding foundations (BF) } \\
\hline 1: Full model & 6.931 & 12 & .862 & 1.00 & $.000[.000, .023]$ & .027 & .070 & & & & \\
\hline 2: No specific $A$ component of $\mathrm{CO}$ & 6.931 & 13 & .906 & 1.00 & $.000[.000, .017]$ & .027 & .067 & 1 & $<.001$ & 1 & $>.999$ \\
\hline 3: No specific $A$ components & 7.476 & 14 & .915 & 1.00 & $.000[.000, .015]$ & .027 & .064 & 2 & .545 & 1 & .460 \\
\hline 4: No specific $A$ component of $\mathrm{CO}$ and & 7.230 & 14 & .925 & 1.00 & $.000[.000, .013]$ & .028 & .064 & 2 & .299 & 1 & .585 \\
\hline \multicolumn{12}{|l|}{$C$ component of BF } \\
\hline \multicolumn{12}{|c|}{ Self-transcendence (ST) and Individualizing foundations (IF) } \\
\hline 1: Full model & 11.372 & 12 & .497 & 1.00 & $.000[.000, .041]$ & .034 & .078 & & & & \\
\hline $\begin{array}{l}\text { 2: No } C \text { component of ST and specific } A \\
\text { component of IF }\end{array}$ & 11.372 & 14 & .657 & 1.00 & $.000[.000, .034]$ & .034 & .071 & 1 & $<.001$ & 2 & $>.999$ \\
\hline $\begin{array}{l}\text { 3: No } C \text { component of ST and specific } D \\
\text { component of IF }\end{array}$ & 11.648 & 14 & .635 & 1.00 & $.000[.000, .035]$ & .040 & .072 & 1 & .276 & 2 & .871 \\
\hline $\begin{array}{l}\text { 4: No } C \text { component of ST and specific } \\
A \text { and } D \text { components of IF }\end{array}$ & 11.651 & 15 & .705 & 1.00 & $.000[.000, .031]$ & .041 & .068 & 2 & .279 & 1 & .597 \\
\hline
\end{tabular}

Note. Comp. = compared with model. Numbers reflect the order of model fitting. 
A

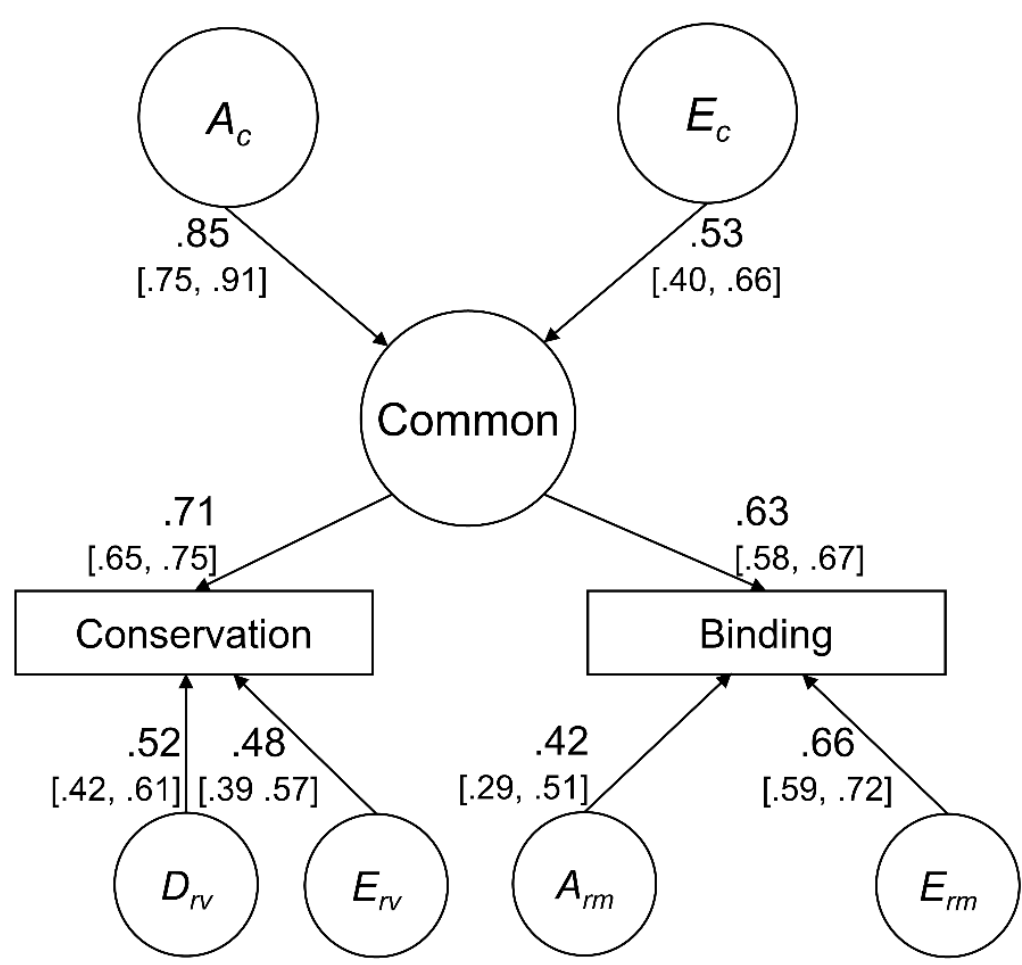

B

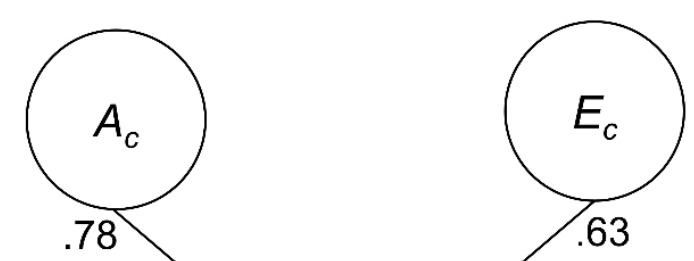

$[.56, .69]$

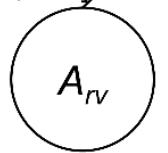

$[.43, .77]$

$[.64, .90]$

.39

$[.35, .43]$

Self-transcendence

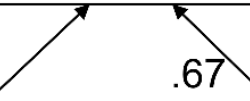

$[.61, .74]$

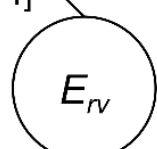

77

$[.69, .85]$

Individualizing

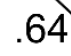

$[.53, .72]$

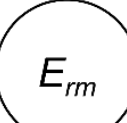

Figure 6. Most parsimonious bivariate twin models for (A) Conservation and Binding foundations and (B) Self-transcendence and Individualizing foundations with standardized parameter estimates. Bootstrapped 95\% confidence intervals (Efron, 1987) are shown in brackets. 


\section{Discussion}

We investigated structural and source-related convergence between basic value orientations and moral foundations. In general, the analyses pointed to the conclusion that these two constructs are empirically related but distinct. Conservation and Binding foundations showed partial structural convergence primarily due to a common genetic basis, but twin model analyses also yielded unique genetic variance in both dimensions. Selftranscendence and Individualizing foundations diverged on a structural level, but showed a partial genetic convergence. That is, the entire genetic variance in Individualizing foundations fully overlapped with the genetic variance in Self-transcendence, but not vice versa. We next discuss the conceptual and measurement-related implications of the findings in greater detail.

\subsection{Divergent Constructs}

We found a substantial genetic link and a moderate environmental correlation between Conservation and Binding foundations. Given the partial structural convergence of both constructs, this could depict a content-wise overlap. Alternatively, this could reflect a third characteristic that overlaps with both dimensions. For example, the common factor may represent existential motives, such as the needs for security and stability (Jost, Federico, \& Napier, 2009; Jost, Glaser, Kruglanski, \& Sulloway, 2003; Schwartz, 2006). The shared unique environmental factors could reflect individual experiences that fuel these existential motives in the face of threat. Past research on socio-political attitudes has shown that people adopt more conservative attitudes following threat-inducing events (e.g., terror attacks; Bonanno \& Jost, 2006; Echebarria-Echabe \& Fernández-Guede, 2006; Huddy \& Feldman, 2011), enduring threatening circumstances (Doty, Peterson, \& Winter, 1991; McCann, 1997; Sales, 1973), and anticipating threats (e.g., due to global warming; Fritsche, Cohrs, Kessler, \& Bauer, 2012; for meta-analyses, see Onraet, Van Hiel, Dhont, \& Pattyn, 2013, and Jost, Stern, Rule, \& Sterling, 2017). This might result from adaptive changes in the moral evaluation of certain political actions and of their necessity in the face of threat. Thus, threatening events may affect people's value orientations and (moral) justification for certain political steps in times of threat, even though they do not necessarily alter people's core motives.

Similarly, the common factor accounting for structural and genetic overlap between Self-transcendence and Individualizing foundations may reflect variance in further core human motives, such as the search for communion and social inclusion. Or it may reflect 
individual differences in the core tendency how individuals deal with the conflict between social life goals (i.e., "how can I get along") and personal life goals (i.e., "how can I get ahead"; McAdams, 2015).

Our analyses revealed that only a moderate variance proportion of Individualizing foundations overlapped with a small variance proportion of Self-transcendence. The common factor fully accounted for genetic variance in Individualizing foundations, whereas the largest proportion of genetic variance in Self-transcendence was dimension-specific. The small total variance in Individualizing foundations may partly explain this finding of imbalance. Since most people agree that care and fairness are highly relevant, the high social desirability of the item contents may have resulted in a ceiling effect that decreased the total variance of Individualizing foundations. The relatively high average scores, smaller standard deviations, and left-skewness of relevant items (see care as well as fairness items in Table A3) are in line with this interpretation. A reduced variance may also lead to a comparably smaller self-other agreement on Individualizing foundations, which corresponds to past findings (Helzer et al., 2014). The measurement of Self-transcendence as bipolar dimension may be comparably less biased by socially desirable responding because it is based on a more indirect approach for capturing goal preferences related to social (e.g., benevolence) versus personal (e.g., power) outcomes.

Notably, we found both value orientations dimensions to be more heritable than their counterpart dimension of moral foundations. This may indicate that the two characteristics are at different (core vs. surface) layers of personality (Kandler, Zimmermann, \& McAdams, 2014). Specifically, value orientations may be dispositional because they show a moderate heritability and can be captured in children within the first decade of life (see Kandler et al., 2016). In contrast, moral foundations could represent characteristic adaptations that show larger environmental variance than dispositional traits (Asendorpf \& Motti-Stefanidi, 2018; Kandler et al., 2014). In addition to critical life events (see above) and measurement error, these unique environmental factors may represent a "shared reality" in different social contexts that shape individual differences in moral foundations. This shared reality is important in forming and maintaining interpersonal relationships (Hardin \& Conley, 2001; Jost, Ledgerwood, \& Hardin, 2008), which serve relational motives (Jost et al., 2009). Relational motives refer to the drive for affiliation, political and social identification, and need for shared reality and solidarity. Consequently, these relational motives might induce deviation from individual motivational goals in favor of agreement within one's social 
environment (e.g., friends, spouses, work environments, and other social groups) regarding "right" and "wrong", ultimately increasing within-family differences.

\subsection{Rater Specificity and Residual Variance}

We found that, in addition to small to moderate proportions of dimension specificity and rater specificity, more than one third of variance in self- and informant reports on Binding foundations and Self-transcendence did not overlap, pointing to factors that act to reduce true score variance and, thus, reliability of measures in our analyses. Those factors may not only represent random error of measurement, but also systematic influences. In other words, despite a considerable self-other agreement in line with past research (e.g., Dobewall, Aavik, Konstabel, Schwartz, \& Realo, 2014), there remained a remarkable proportion of variance in Binding foundations and Self-transcendence that is rater-specific and independent from the rater specificity across constructs. Given that this was not a consistent finding across all four dimensions, we deem it unlikely that this is due to a lack of observability (Vazire \& Carlson, 2011). Residual variance components may reflect rater-specific perspectives on dimension-specific information beyond error of measurement.

With respect to Binding foundations, abstract item wordings may increase divergence in raters' specific understanding of items. Some items, for example, broadly refer to abstract concepts such as loyalty, betrayal, decency, and unnatural acts. These concepts, in particular, may be differently understood by targets and informants. Moreover, informants, required to identify and interpret available relevant cues (Funder, 1995, 2012), do not only have to infer how the targets understand these concepts, but also how observations of the targets' behavior provide information on the target's moral concern for these concepts.

Regarding Self-transcendence, informants may additionally rely on an assumed similarity between themselves and the targets (Paunonen \& Kam, 2014). Past studies found that, particularly for socially relevant characteristics, assumed similarity between wellacquainted, close people is larger than actual similarity, and these effects were larger for Selftranscendence than Conservation (Lee et al., 2009; Thielmann, Hilbig, \& Zettler, 2020; Study 1). Consequently, informants that partially based their ratings on an assumed similarity in Self-transcendence with targets may have contributed to an increase in rater divergence.

\subsection{Limitations and Future Directions}

We could not test our assumption that the dimensions - or their common factors reflect world beliefs or core human motives. To investigate this, future research could build on the dual-process motivational (DPM) model of ideology and prejudice (Duckitt, 2001; 
Duckitt \& Sibley, 2017). The DPM model holds that social world beliefs and personality trait dispositions jointly shape individual differences in sociopolitical attitudes. Past studies found both value orientations and moral foundations to be correlated with those personality trait dispositions and sociopolitical attitudes (e.g., Anglim, Knowles, Dunlop, \& Marty, 2017; Cohrs, Moschner, Maes, \& Kielmann, 2005; Heaven, Organ, Supavadeeprasit, \& Leeson, 2006; Kugler, Jost, \& Noorbaloochi, 2014; Leone, Desimoni, \& Chirumbolo, 2012; ZeiglerHill, Noser, Roof, Vonk, \& Marcus, 2015). This could also provide insight into the interplay among the present dimensions (as potential world beliefs), personality trait dimensions, and sociopolitical attitudes.

Longitudinal behavior genetic studies may shed light on the nature of the common factor and specific nonshared environmental contributions. Do these factors reflect the proposed motives and threatening circumstances, a shared reality, or both? In addition, we could only consider self-reports in the twin models. While this is common practice, it may lead to inflated genetic estimates and correlations due to genetic influences on response biases (Kandler, Riemann, Spinath, \& Angleitner, 2010). Moreover, this approach does not permit disentangling unique environmental effects from measurement error. Our procedure of generating factor scores may have reduced the impact of certain response biases, but a multirater twin model design would be superior in this regard. A multi-rater twin design could also provide insight into rater-specific sources, especially for evaluative characteristics (ZapkoWillmes \& Kandler, 2018).

The constructs studied in the current investigation are claimed to be cross-culturally valid (Graham et al., 2016; Schwartz, 2017). Research can and should assess whether individual differences in the characteristics, their covariance, and underlying sources of variance are also cross-culturally valid, especially in light of research calling this into question (Boer \& Fischer, 2013).

Considering that we found little variance in Individualizing foundations, researchers could construct morality measures by balancing items of conflicting moral concerns. Modeling moral concerns as trade-offs between moral consequences may more accurately reflect the moral dilemmas that are commonly used in moral psychological research. This measurement strategy might help not only to mitigate response biases such as socially desirable responding, but also to uncover stronger differences between people in moral concerns.

Our findings do not necessarily have implications for other, non-pluralistic approaches to morality (e.g., Janoff-Bulman \& Carnes, 2013; Schein \& Gray, 2015). Thus, to 
achieve a broader understanding of the links between values and moral judgment, it would be worthwhile to investigate the associations between these models of morality and the TBV.

We relied on an underpowered twin sample size, which may have led to undetected common $C$ effects. Future studies should replicate our findings using a sufficiently large twin sample that allows for a more reliable differentiation between $A$ and $C$ effects.

Finally, we applied a short version of the Moral Foundations Questionnaire that may not have adequately captured the moral foundations as theoretically outlined (Haidt \& Joseph, 2004, 2007). Future research on the overlap of moral foundations and value orientations should use a broader measure of moral foundations that better captures the bandwidth of the proposed constructs.

\subsection{Conclusion}

The current investigation provided strong evidence that basic value orientations and moral foundations can be considered distinct psychological constructs, but they are empirically and systematically associated. Analyses of different rater perspectives revealed only moderate structural convergence and suggested potential differences in measurement specificity (e.g., rater-specific perspectives) within and across dimensions. Moreover, we found the covariance of value orientations and moral foundations to be primarily attributable to genetic factors, with a common factor of Self-transcendence and Individualizing fully accounting for the genetic variance in Individualizing foundations.

This study is a first attempt to integrate and locate independently established, conceptually comparable frameworks of evaluative characteristics within a broad nomological net of several characteristics to describe individual differences in personality and potentially account for individual differences in conative behavior. Our findings advance the understanding of the structural and source-related commonalities and differences between core value orientations and moral foundations. Future cross-cultural and longitudinal research will need to enrich them, for example, by studying their construct-valid embedding in a broader network of potential personality-relevant characteristics. 


\section{References}

Abbot, P., Abe, J., Alcock, J., Alizon, S., Alpedrinha, J. A. C., Andersson, M., . . Zink, A. (2011). Inclusive fitness theory and eusociality. Nature, 471, E1-E4. doi:10.1038/nature09831

Adler, A. (1956). The value concept in sociology. American Journal of Sociology, 62, 272-279. doi:10.1086/222004

Anglim, J., Knowles, E. R., Dunlop, P. D., \& Marty, A. (2017). HEXACO personality and Schwartz's basic values: A facet-level analysis. Journal of Research in Personality, 68, 23-31. doi:10.1016/j.jrp.2017.04.002

Arbuckle, J. L. (2016). Amos (Version 24.0) [Computer program]. Chicago, IL, USA: IBM SPSS.

Asendorpf, J. B., \& Motti-Stefanidi, F. (2018). Mediated disposition-environment transactions: the DAE model. European Journal of Personality, 32, 167-185. doi:10.1002/per.2118

Bardi, A., Lee, J. A., Hofmann-Towfigh, N., \& Soutar, G. (2009). The structure of intraindividual value change. Journal of Personality and Social Psychology, 97, 913-929. doi:10.1037/a0016617

Bilsky, W. (2008). Die Struktur der Werte und ihre Stabilität über Instrumente und Kulturen. [The structure of values and their stability across measures and cultures.] In E. H. Witte (Ed.), Sozialpsychologie und Werte (pp. 63-89). [Social psychology and values.] Lengerich, Germany: Pabst.

Bleidorn, W., Kandler, C., \& Caspi, A. (2014). The behavioral genetics of personality development in adulthood - classic, contemporary, and future trends. European Journal of Personality, 28, 244-255. doi:10.1002/per.1957

Boer, D., \& Fischer, R. (2013). How and when do basic values guide our attitudes and sociality? Explaining cross-cultural variability in attitude-value linkages. Psychological Bulletin, 139, 1113-1147. doi:10.1037/a0031347

Bonanno, G. A., \& Jost, J. T. (2006). Conservative shift among high-exposure survivors of the September 11th terrorist attacks. Basic and Applied Social Psychology, 28, 311-323. doi:10.1207/s15324834basp2804_4

Borg, I., \& Bardi, A. (2016). Should ratings of the importance of personal values be centered? Journal of Research in Personality, 63, 95-101. doi:10.1016/j.jrp.2016.05.011

Braithwaite, V. A., \& Scott, W. A. (1991). Values. In J. P. Robinson, P. Shaver \& L. Wrightsman (Eds.), Measures of personality and social psychological attitudes (pp. 661-753). New York: Academic Press.

Briley, D., Livengood, J., \& Derringer, J. (2018). Behavior genetic frameworks of causal reasoning for personality psychology. European Journal of Personality, 32, 202-220. doi:10.1002/per.2153

Browne, M. W., \& Cudeck, R. (1993). Alternative ways of assessing model fit. In K. A. Bollen \& J. S. Long (Eds.), Testing structural equation models (pp. 136-162). Newbury Park, CA: Sage. 
Bryant, F. B., \& Satorra, A. (2012). Principles and practice of scaled difference chi-square testing. Structural Equation Modeling, 19, 372-398. doi:10.1080/10705511.2012.687671

Campbell, D. T. (1963). Social attitudes and other acquired behavioral dispositions. In S. Koch (Ed.), Psychology: A study of a science (Vol. 6, pp. 94-172). New York, NY: McGraw-Hill. doi:10.1037/10590-003

Campbell, D. T., \& Fiske, D. W. (1959). Convergent and discriminant validation by the multitraitmultimethod matrix. Psychological Bulletin, 56, 81-105.

Cheung, G. W., \& Rensvold, R. B. (2002). Evaluating goodness-of-fit indexes for testing measurement invariance. Structural Equation Modeling, 9, 233-255. doi:10.1207/S15328007SEM0902_5

Cohrs, J. C., Moschner, B., Maes, J., \& Kielmann, S. (2005). The motivational bases of right-wing authoritarianism and social dominance orientation: Relations to values and attitudes in the aftermath of September 11, 2001. Personality and Social Psychology Bulletin, 31, 14251434. doi:10.1177/0146167205275614

Cornwell, J. F. M, \& Higgins, E. T. (2019). Beyond value in moral phenomenology: the role of epistemic and control experiences. Frontiers in Psychology, 10, 2430. doi:10.3389/fpsyg.2019.02430

Cronbach, L. J., \& Meehl, P. E. (1955). Construct validity in psychological tests. Psychological Bulletin, 52, 281-302. doi:10.1037/h0040957

Curry, O. S., Jones Chesters, M., \& Van Lissa, C. J. (2019). Mapping morality with a compass: testing the theory of 'morality-as-cooperation' with a new questionnaire. Journal of Research in Personality, 78, 106-124. doi:10.1016/j.jrp.2018.10.008

Danioni, F., \& Barni, D. (2020). Value priorities, impression management and self-deceptive enhancement: once again, much substance and a little bit of style. The Journal of Social Psychology, 1-14. doi:10.1080/00224545.2020.1778619

Dobewall, H., Aavik, T., Konstabel, K., Schwartz, S. H., \& Realo, A. (2014). A comparison of selfother agreement in personal values versus the Big Five personality traits. Journal of Research in Personality, 50, 1-10. doi:10.1016/j.jrp.2014.01.004

Doty, R. M., Peterson, B. E., \& Winter, D. G. (1991). Threat and authoritarianism in the United States, 1978-1987. Journal of Personality and Social Psychology, 61, 629-640. doi:10.1037/0022-3514.61.4.629

Duckitt, J. (2001). A dual-process cognitive-motivational theory of ideology and prejudice. In Advances in experimental social psychology (Vol. 33, pp. 41-113). Academic Press.

Duckitt, J., \& Sibley, C. G. (2017). The dual process motivational model of ideology and prejudice. In C. G. Sibley \& F. K. Barlow (Eds.), The Cambridge handbook of the psychology of prejudice (pp. 188-221). New York, NY: Cambridge University Press. 
Echebarria-Echabe, A., \& Fernández-Guede, E. (2006). Effects of terrorism on attitudes and ideological orientation. European Journal of Social Psychology, 36, 259-265. doi:10.1002/ejsp.294

Eid, M., Lischetzke, T., Nussbeck, F. W., \& Trierweiler, L. I. (2003). Separating trait effects from trait-specific method effects in multitrait-multimethod models: a multiple-indicator CT-C (M1) model. Psychological Methods, 8, 38-60. doi:10.1037/1082-989X.8.1.38

Efron, B. (1987). Better bootstrap confidence intervals. Journal of the American Statistical Association, 82, 171-185. doi:10.1080/01621459.1987.10478410

Fede, S. J., \& Kiehl, K. A. (2020). Meta-analysis of the moral brain: patterns of neural engagement assessed using multilevel kernel density analysis. Brain Imaging and Behavior, 14, 534-547. doi:10.1007/s11682-019-00035-5

Federico, C. M., Weber, C. R., Ergun, D., \& Hunt, C. (2013). Mapping the connections between politics and morality: the multiple sociopolitical orientations involved in moral intuition. Political Psychology, 34, 589-610. doi:10.1111/pops.12006

Feldman, G. (2018). Personal values and moral foundations: towards an integrated perspective by examining meaning, structure, and relations. Unpublished manuscript. doi:10.13140/RG.2.2.32570.49600/1

Feldman, G., Chao, M. M., Farh, J.-L., \& Bardi, A. (2015). The motivation and inhibition of breaking the rules: basic values structures predict unethicality. Journal of Research in Personality, 59, 69-80. doi:10.1016/j.jrp.2015.09.003

Fritsche, I., Cohrs, J. C., Kessler, T., \& Bauer, J. (2012). Global warming is breeding social conflict: the subtle impact of climate change threat on authoritarian tendencies. Journal of Environmental Psychology, 32, 1-10. doi:10.1016/j.jenvp.2011.10.002

Fritzsche, D., \& Oz, E. (2007). Basic values' influence on the ethical dimension of decision making. Journal of Business Ethics, 75, 335-343. doi:10.1007/s10551-006-9256-5

Funder, D. C. (1995). On the accuracy of personality judgment: A realistic approach. Psychological Review, 102, 652-670. doi:10.1037/0033-295X.102.4.652

Funder, D. C. (2012). Accurate personality judgment. Current Directions in Psychological Science, 21, 177-182. doi:10.1177/0963721412445309

Goodwin, J. L., Williams, A. L., \& Snell Herzog, P. (2020). Cross-cultural values: a meta-analysis of major quantitative studies in the last decade (2010-2020). Religions, 11, 396. doi:10.3390/rel11080396

Graham, J. (2015). Explaining away differences in moral judgment: comment on Gray and Keeney (2015). Social Psychological and Personality Science, 6, 869-873. doi:10.1177/1948550615592242

Graham, J., Haidt, J., Motyl, M., Meindl, P., Iskiwitch, C., \& Mooijman, M. (2018). Moral foundations theory: on the advantages of moral pluralism over moral monism. In K. Gray \& J. 
Graham (Eds.), Atlas of moral psychology (pp. 211-222). New York, NY: The Guilford Press.

Graham, J., Haidt, J., \& Nosek, B. A. (2009). Liberals and conservatives rely on different sets of moral foundations. Journal of Personality and Social Psychology, 96, 1029-1046. doi:10.1037/a0015141

Graham, J., Meindl, P., Beall, E., Johnson, K. M., \& Zhang, L. (2016). Cultural differences in moral judgment and behavior, across and within societies. Current Opinion in Psychology, 8, 125130. doi:10.1016/j.copsyc.2015.09.007

Graham, J., Nosek, B. A., Haidt, J., Iyer, R., Koleva, S., \& Ditto, P. H. (2011). Mapping the moral domain. Journal of Personality and Social Psychology, 101, 366-385. doi:10.1037/a0021847

Gray, K., \& Graham, J. (Eds.) (2018). Atlas of moral psychology. New York, NY: The Guilford Press.

Gray, K., \& Keeney, J. E. (2015a). Impure, or just weird? Scenario sampling bias raises questions about the foundations of morality. Social Psychology and Personality Science, 6, 859-868. doi:10.1177/1948550615592241

Gray, K., \& Keeney, J. E. (2015b). Disconfirming moral foundations theory on its own terms: reply to Graham (2015). Social Psychological and Personality Science, 6, 874-877. doi:10.1177/1948550615592243

Greene, J. D., Sommerville, R. B., Nystrom, L. E., Darley, J. M., \& Cohen, J. D. (2001). An fMRI investigation of emotional engagement in moral judgment. Science, 293, 2105-2108. doi:10.1126/science. 1062872

Haidt, J. (2001). The emotional dog and its rational tail: a social intuitionist approach to moral judgment. Psychological Review, 108, 814-834. doi:10.1037/0033-295X.108.4.814

Haidt, J., Graham, J., \& Joseph, C. (2009). Above and below left-right: ideological narratives and moral foundations. Psychological Inquiry, 20, 110-119. doi:10.1080/10478400903028573

Haidt, J., \& Joseph, C. (2004). Intuitive ethics: how innately prepared intuitions generate culturally variable virtues. Dedalus: Special Issue on Human Nature, 133, 55-66. doi:10.1162/0011526042365555

Haidt, J., \& Joseph, C. (2007). The moral mind: how 5 sets of innate intuitions guide the development of many culture-specific virtues, and perhaps even modules. In P. Carruthers, S. Laurence, \& S. Stich (Eds.), The innate mind (Vol. 3, pp. 367-391). New York, NY: Oxford University Press.

Haidt, J., \& Kesebir, S. (2010). Morality. In S.T. Fiske, D. Gilbert, \& G. Lindzey (Eds.), Handbook of social psychology (5th ed., pp. 797-832). Hoboken, NJ: Wiley.

Hardin, C. D., \& Conley, T. D. (2001). A relational approach to cognition: shared experience and relationship affirmation in social cognition. In G. B. Moskowitz (Ed.), Cognitive social psychology: The Princeton symposium on the legacy and future of social cognition (pp. 317). Mahwah, NJ: Lawrence Erlbaum Associates. 
He, J., \& van de Vijver, F. J. (2015). Self-presentation styles in self-reports: linking the general factors of response styles, personality traits, and values in a longitudinal study. Personality and Individual Differences, 81, 129-134. doi:10.1016/j.paid.2014.09.009

Heaven, P., Organ, L., Supavadeeprasit, S., \& Leeson, P. (2006). War and prejudice: A study of social values, right-wing authoritarianism, and social dominance orientation. Personality and Individual Differences, 40, 599-608. doi:10.1016/j.paid.2005.08.005

Heider, F. (1958). The psychology of interpersonal relations. New York, NY: Wiley.

Helzer, E. G., Furr, R. M., Hawkins, A., Barranti, M., Blackie, L. E. R., \& Fleeson, W. (2014). Agreement on the perception of moral character. Personality and Social Psychology Bulletin, 40, 1698-1710. doi:10.1177/0146167214554957

Higgins, E. T. (2016). What is value? Where does it come from? A psychological perspective. In T. Brosch \& D. Sander (Eds.), Handbook of value: perspectives from economics, neuroscience, philosophy, psychology, and sociology (pp. 43-62). Oxford, UK: Oxford University Press.

Hu, L., \& Bentler, P. M. (1999). Cutoff criteria for fit indexes in covariance structure analysis: conventional criteria versus new alternatives. Structural Equation Modeling: A Multidisciplinary Journal, 6, 1-55. doi:10.1080/10705519909540118

Huddy, L., \& Feldman, S. (2011). Americans respond politically to 9/11: understanding the impact of the terrorist attacks and their aftermath. American Psychologist, 66, 455-467. doi:10.1037/a0024894

Janoff-Bulman, R., \& Carnes, N. C. (2013). Surveying the moral landscape moral motives and groupbased moralities. Personality and Social Psychology Review, 17, 219-236. doi:10.1177/1088868313480274

Joeckel, S., Bowman, N. D., \& Dogruel, L. (2012). Gut or game? The influence of moral intuitions on decisions in video games, Media Psychology, 15, 460-485. doi:10.1080/15213269.2012.727218

Jost, J. T., Federico, C. M., \& Napier, J. L. (2009). Political ideology: its structure, functions, and elective affinities. Annual Review of Psychology, 60, 307-337. doi:10.1146/annurev.psych.60.110707.163600

Jost, J. T., Glaser, J., Kruglanski, A. W., \& Sulloway, F. J. (2003). Political conservatism as motivated social cognition. Psychological Bulletin, 129, 339-375. doi:10.1037/0033-2909.129.3.339

Jost, J. T., Ledgerwood, A., \& Hardin, C. D. (2008). Shared reality, system justification, and the relational basis of ideological beliefs. Social and Personality Psychology Compass, 2, 171186. doi:10.1111/j.1751-9004.2007.00056.x

Jost, J. T., Stern, C., Rule, N. O., \& Sterling, J. (2017). The politics of fear: Is there an ideological asymmetry in existential motivation? Social Cognition, 35, 324-353. doi:10.1521/soco.2017.35.4.324

Kahneman, D. (2011). Thinking, fast and slow. New York, NY: Farrar, Strauss, Giroux. 
Kandler, C., Gottschling, J., \& Spinath, F. M. (2016). Genetic and environmental parent-child transmission of value orientations: an extended twin family study. Child Development, 87 , 270-284. doi:10.1111/cdev.12452

Kandler, C., Penner, A., Richter, J., \& Zapko-Willmes, A. (2019). The Study of Personality Architecture and Dynamics (SPeADy): a longitudinal and extended twin family study. Twin Research and Human Genetics, 22, 548-553. doi:10.1017/thg.2019.62

Kandler, C., Riemann, R., Spinath, F. M., \& Angleitner, A. (2010). Sources of variance in personality facets: a multiple-rater twin study of self-peer, peer-peer, and self-self (dis)agreement. Journal of Personality, 78, 1565-1594. doi:0.1111/j.1467-6494.2010.00661.x

Kandler, C., \& Zapko-Willmes, A. (2017). Theoretical perspectives on the interplay of nature and nurture in personality development. In J. Specht (Ed.), Personality development across the lifespan (pp. 101-115). Elsevier Academic Press. doi:10.1016/B978-0-12-804674-6.00008-9

Kandler, C., Zimmermann, J., \& McAdams, D. P. (2014). Core and surface characteristics for the description and theory of personality differences and development. European Journal of Personality, 28, 231-243. doi:10.1002/per.1952

Keller, L. M., Bouchard, T. J., Arvey, R. D., Segal, N. L., \& Dawis, R. V. (1992). Work values: genetic and environmental influences. Journal of Applied Psychology, 77, 79-88. doi:10.1037/0021-9010.77.1.79

Klößner, S., \& Klopp, E. (2017). Metric measurement invariance of latent variables: foundations, testing, and correct interpretation. Unpublished manuscript. doi:10.13140/RG.2.2.26491.62240

Kluckhohn, C. (1951). Values and value-orientations in the theory of action. An exploration in definition and classification. In T. Parsons \& E. A. Shils (Eds.), Toward a general theory of action (pp. 388-433). Cambridge, MA: Harvard University Press. doi:10.4159/harvard.9780674863507

Knafo, A., \& Spinath, F. M. (2011). Genetic and environmental influences on girls' and boys' gendertyped and gender-neutral values. Developmental Psychology, 47, 726-731. doi:10.1037/a0021910

Kohlberg, L. (1963). The development of children's orientations toward a moral order: I. sequence in the development of moral thought. Vita Humana, 6, 11-33.

Kugler, M., Jost, J. T., \& Noorbaloochi, S. (2014). Another look at moral foundations theory: Do authoritarianism and social dominance orientation explain liberal-conservative differences in "moral” intuitions? Social Justice Research, 27, 413-431. doi:10.1007/s11211-014-0223-5

Le, H., Schmidt, F. L., Harter, J. K., \& Lauver, K. J. (2010). The problem of empirical redundancy of constructs in organizational research: an empirical investigation. Organizational Behavior and Human Decision Processes, 112, 112-125. doi:10.1016/j.obhdp.2010.02.003 
Lee, K., Ashton, M. C., Ogunfowora, B., Bourdage, J. S., \& Shin, K. H. (2010). The personality bases of socio-political attitudes: the role of honesty-humility and openness to experience. Journal of Research in Personality, 44, 115-119. doi:10.1016/j.jrp.2009.08.007

Lee, K., Ashton, M. C., Pozzebon, J. A., Visser, B. A., Bourdage, J. S., \& Ogunfowora, B. (2009). Similarity and assumed similarity in personality reports of well-acquainted persons. Journal of Personality and Social Psychology, 96, 460-472. doi:10.1037/a0014059

Leone, L., Desimoni, M., \& Chirumbolo, A. (2012). HEXACO, social worldviews and socio-political attitudes: A mediation analysis. Personality and Individual Differences, 53, 995-1001. doi:10.1016/j.paid.2012.07.016

Levitin, T. (1968). Values. In J. P. Robinson \& P. R. Shaver (Eds.), Measures of social psychological attitudes (pp. 405-501). Ann Arbor: University of Michigan Press, Survey Research Center, Institute for Social Research.

Little, T. D. (2013). Longitudinal structural equation modeling. New York, NY: The Guilford Press.

Mamsori, S., Rezaee, Z., Homayoun, S., \& Noghondari, A. T. (2015). Do individual traits associate with ethical judgment? Journal of Management and Sustainability, 5, 85-98. doi:10.5539/jms.v5n3p85

Martin, N. G., Eaves, L. J., Heath, A. C., Jardine, R., Feingold, L. M., \& Eysenck, H. J. (1986). Transmission of social attitudes. Proceedings of the National Academy of Sciences of the United States of America, 83, 4364-4368. doi:10.1073/pnas.83.12.4364

McAdams, D. P. (2015). The art and science of personality development. New York, NY: The Guilford Press.

McAdams, D. P., \& Pals, J. L. (2006). A new Big Five: fundamental principles for an integrative science of personality. American Psychologist, 61, 204-217. doi:10.1037/0003066X.61.3.204

McCann, S. J. H. (1997). Threatening times, "strong" presidential vote winners, and the victory margin, 1824-1964. Journal of Personality and Social Psychology, 73, 160-170. doi:10.1037/0022-3514.73.1.160

McGue, M., \& Bouchard, T. J. Jr. (1984). Adjustment of twin data for the effects of age and sex. Behavior Genetics, 14, 325-343. doi:10.1007/BF01080045

Milfont, T. L., Milojev, P., \& Sibley, C. G. (2016). Values stability and change in adulthood: a 3-year longitudinal study of rank-order stability and mean-level differences. Personality and Social Psychology Bulletin, 42, 572-588. doi:10.1177/0146167216639245

Moll, J., Zahn, R., de Oliveira-Souza, R., Krueger, F., \& Grafman, J. (2005). The neural basis of human moral cognition. Nature Reviews Neuroscience, 6, 799-809. doi:10.1038/nrn1768

Morris, C. (1956). Varieties of human value. Chicago, IL: University of Chicago Press.

Nowak, M., Tarnita, C. \& Wilson, E. (2010). The evolution of eusociality. Nature, 466, 1057-1062. doi:10.1038/nature09205 
Onraet, E., Van Hiel, A., Dhont, K., \& Pattyn, S. (2013). Internal and external threat in relationship with right-wing attitudes. Journal of Personality, 81, 233-248. doi:10.1111/jopy.12011

Parsons, T. (1951). The social system. Glencoe, IL: The Free Press.

Paunonen, S. V., \& Kam, C. (2014). The accuracy of roommate ratings of behaviors versus beliefs. Journal of Research in Personality, 52, 55-67. doi:10.1016/j.jrp.2014.07.006

Piaget, J. (2015). Das moralische Urteil des Kindes [The moral judgment of the child]. In R. Kohler (Ed.), Schlüsseltexte in 6 Bänden (Vol. 3). [Key texts in six volumes]. Stuttgart, Germany: Klett-Cotta. (Original work published in 1932)

Podsakoff, P. M., MacKenzie, S. B., Lee, J. Y., \& Podsakoff, N. P. (2003). Common method biases in behavioral research: a critical review of the literature and recommended remedies. Journal of Applied Psychology, 88, 879-903. doi:10.1037/0021-9010.88.5.879

R Core Team (2017). R: A language and environment for statistical computing. R Foundation for Statistical Computing, Vienna, Austria. https://www.R-project.org/

Rai, T. S., \& Fiske, A. P. (2011). Moral psychology is relationship regulation: moral motives for unity, hierarchy, equality, and proportionality. Psychological Review, 118, 57-75. doi:10.1037/a0021867

Raykov, T., Marcoulides, G. A., and Li, C.-H. (2012). Measurement invariance for latent constructs in multiple populations. Educational and Psychological Measurement, 72, 954-974. doi:10.1177/0013164412441607

Renner, W., Kandler, C., Bleidorn, W., Riemann, R., Angleitner, A., Spinath, F. M., \& MenschikBendele, J. (2012). Human values: genetic and environmental effects on five lexically derived domains and their facets. Personality and Individual Differences, 52, 89-93. doi:10.1016/j.paid.2011.09.003

Revelle, W. (2017). psych: procedures for personality and psychological research. Northwestern University, Evanston, Illinois, USA. https://CRAN.R-project.org/package=psych

Rohan, M. J. (2000). A rose by any name? The values construct. Personality and Social Psychology Review, 4, 255-277. doi:10.1207/S15327957PSPR0403_4

Rokeach, M. (1973). The nature of human values. New York, NY: The Free Press.

Rosseel, Y. (2012). lavaan: An R package for structural equation modeling. Journal of Statistical Software, 48, 1-36. http://www.jstatsoft.org/v48/i02/

Roth, M., \& Altmann, T. (2019). A multi-informant study of the influence of targets' and perceivers' social desirability on self-other agreement in ratings of the HEXACO personality dimensions. Journal of Research in Personality, 78, 138-147. doi:10.1016/j.jrp.2018.11.008

RStudio Team (2016). RStudio: integrated development for R. RStudio, Inc., Boston, MA. http://www.rstudio.com/

Sales, S. (1973). Threat as a factor in authoritarianism: an analysis of archival data. Journal of Personality and Social Psychology, 28, 44-57. doi:10.1037/h0035588 
Satorra, A., \& Bentler, P. M. (2001). A scaled difference chi-square test statistic for moment structure analysis. Psychometrika, 66, 507-514. doi:10.1007/BF02296192

Schein, C., \& Gray, K. (2015). The unifying moral dyad: liberals and conservatives share the same harm-based moral template. Personality and Social Psychology Bulletin, 41, 1147-1163. doi:10.1177/0146167215591501

Schein, C., \& Gray, K. (2018). The theory of dyadic morality: reinventing moral judgment by redefining harm. Personality and Social Psychology Review, 22, 32-70. doi:10.1177/1088868317698288

Schermer, J. A., Feather, N. T., Zhu, G., \& Martin, N. G. (2008). Phenotypic, genetic, and environmental properties of the portrait values questionnaire. Twin Research and Human Genetics, 11, 531-537. doi:10.1375/twin.11.5.531

Schermer, J. A., Vernon, P. A., Maio, G. R., \& Jang, K. L. (2011). A behavior genetic study of the connection between social values and personality. Twin Research and Human Genetics, 14, 3, 233-239. doi:10.1375/twin.14.3.233

Schwartz, S. H. (1992). Universals in the content and structure of values: theory and empirical tests in 20 countries. In M. Zanna (Ed.), Advances in experimental social psychology (Vol. 25, pp. 165). New York, NY: Academic Press.

Schwartz, S. H. (1994). Are there universal aspects in the content and structure of values? Journal of Social Issues, 50, 19-45. doi:10.1111/j.1540-4560.1994.tb01196.x

Schwartz, S. H. (2005). Robustness and fruitfulness of a theory of universals in individual human values. In A. Tamayo \& J. B. Porto (Eds.), Valores e comportamento nas organizaç atoes [Values and behavior in organizations] (pp. 56-95). Petrópolis, Brazil: Vozes.

Schwartz, S. H. (2006). Les valeurs de base de la personne: Théorie, mesures et applications [Basic human values: Theory, measurement, and applications]. Revue Française de Sociologie, 47, $249-288$.

Schwartz, S. H. (2016). Basic individual values: sources and consequences. In T. Brosch \& D. Sander (Eds.), Handbook of value: perspectives from economics, neuroscience, philosophy, psychology, and sociology (pp. 63-84). Oxford, UK: Oxford University Press.

Schwartz, S. H. (2017). The refined theory of basic values. In S. Roccas \& L. Sagiv (Eds.), Values and behavior: taking a cross-cultural perspective (pp. 51-72). Cham, Switzerland: Springer International Publishing.

Schwartz, S. H., \& Bilsky, W. (1987). Toward a universal psychological structure of human values. Journal of Personality and Social Psychology, 53, 550-562. doi:10.1037/0022-3514.53.3.550

Schwartz, S. H., \& Bilsky, W. (1990). Toward a theory of the universal content and structure of values: extensions and cross-cultural replications. Journal of Personality and Social Psychology, 58, 878-891. doi:10.1037/0022-3514.58.5.878 
Schwartz, S. H., Caprara, G. V., \& Vecchione, M. (2010). Basic personal values, core political values, and voting: a longitudinal analysis. Political psychology, 31, 421-452. doi:10.1111/j.14679221.2010.00764.x

Schwartz, S. H., Cieciuch, J., Vecchione, M., Davidov, E., Fischer, R., Beierlein, C., . . Konty, M. (2012). Refining the theory of basic individual values. Journal of Personality and Social Psychology, 103, 663-688. doi:10.1037/a0029393

semTools Contributors (2016). semTools: useful tools for structural equation modeling. R package version 0.4-14. https://CRAN.R-project.org/package=semTools

Shaffer, J. A., DeGeest, D., \& Li, A. (2016). Tackling the problem of construct proliferation: a guide to assessing the discriminant validity of conceptually related constructs. Organizational Research Methods, 19, 80-110. doi:10.1177/1094428115598239

Sinn, J. S. (2019). Mapping ideology: combining the Schwartz value circumplex with evolutionary theory to explain ideological differences. Evolutionary Psychological Science, 5, 44-57. doi:10.1007/s40806-018-0165-5

Skitka, L. J., \& Conway, P. (2019). Morality. In E. J. Finkel \& R. F. Baumeister (Eds.), Advanced social psychology: The state of the science (pp. 299-323). New York, NY: Oxford University Press.

Smith, M. B. (1969). Social psychology and human values: selected essays. Chicago, IL: Aldine Pub. Co.

Smith, K. B., Alford, J. R., Hibbing, J. R., Martin, N. G., \& Hatemi, P. K. (2017). Intuitive ethics and political orientations: testing moral foundations as a theory of political ideology. American Journal of Political Science, 61, 424-437. doi:10.1111/ajps.12255

Steiger, J. H. (1990). Structural model evaluation and modification: an interval estimation approach. Multivariate Behavioral Research, 25, 173-180. doi:10.1207/s15327906mbr2502_4

Stieger, S., Kandler, C., Tran, U. S., Pietschnig, J., \& Voracek, M. (2017). Genetic and environmental sources of implicit and explicit self-esteem and affect: results from a genetically sensitive multi-group design. Behavior Genetics, 47, 175-192. doi:10.1007/s10519-016-9829-8

Sverdlik, N., Roccas, S., \& Sagiv, L. (2012). Morality across cultures: a values perspective. In M. Mikulincer \& P. R. Shaver (Eds.), The social psychology of morality: exploring the causes of good and evil (pp. 219-236). Washington, DC: American Psychological Association.

Tappolet, C., \& Rossi, M. (2016). What is value? Where does it come from? A philosophical perspective. In T. Brosch \& D. Sander (Eds.), Handbook of value: perspectives from economics, neuroscience, philosophy, psychology, and sociology (pp. 3-22). Oxford, UK: Oxford University Press.

Thielmann, I., Hilbig, B. E., \& Zettler, I. (2020). Seeing me, seeing you: Testing competing accounts of assumed similarity in personality judgments. Journal of Personality and Social Psychology, 118, 172-198. doi:10.1037/pspp0000222 
Thomson, G. H. (1934). The meaning of ' $\mathrm{i}$ ' in the estimate of ' $\mathrm{g}$ '. British Journal of Psychology, 25, 92-99. doi: 10.1111/j.2044-8295.1934.tb00728.x

Thurstone, L. L. (1935). The vectors of mind. Chicago, IL: University of Chicago Press.

Urban, W. M. (1907). Recent tendencies in the psychological theory of values. Psychological Bulletin, 4, 65-72.

Vazire, S., \& Carlson, E. N. (2011). Others sometimes know us better than we know ourselves. Current Directions in Psychological Science, 20, 104-108. doi:10.1177/0963721411402478

Vecchione, M., Schwartz, S., Alessandri, G., Döring, A. K., Castellani, V., \& Caprara, M. G. (2016). Stability and change of basic personal values in early adulthood: an 8-year longitudinal study. Journal of Research in Personality, 63, 111-122. doi:10.1016/j.jrp.2016.06.002

Yuan, K. H., \& Bentler, P. M. (2000). Three likelihood-based methods for mean and covariance structure analysis with nonnormal missing data. Sociological Methodology, 30, 165-200. doi:10.1111/0081-1750.00078

Zahn, R., Moll, J., Paiva, M., Garrido, G., Krueger, F., Huey, E. D., \& Grafman, J. (2009). The neural basis of human social values: evidence from functional MRI. Cerebral Cortex, 19, 276-283. doi:10.1093/cercor/bhn080

Zapko-Willmes, A., \& Kandler, C. (2018). Genetic variance in homophobia: evidence from self- and peer reports. Behavior Genetics, 48, 34-43. doi:10.1007/s10519-017-9884-9

Zeigler-Hill, V., Noser, A. E., Roof, C., Vonk, J., \& Marcus, D. K. (2015). Spitefulness and moral values. Personality and Individual Differences, 77, 86-90. doi:10.1016/j.paid.2014.12.05 